Pontifícia Universidade $C_{\text {atólica }}$

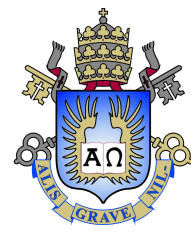

Roberto Simonelli Lee

Productive and Allocative Efficiency of State Owned Enterprises: Evidence from the Brazilian Privatization Program

Dissertação de Mestrado

Dissertation presented to the Programa de Pós-graduação em Economia da PUC-Rio in partial fulfillment of the requirements for the degree of Mestre em Economia .

Advisor : Prof. Leonardo Rezende

Co-advisor: Prof. Gustavo Gonzaga 


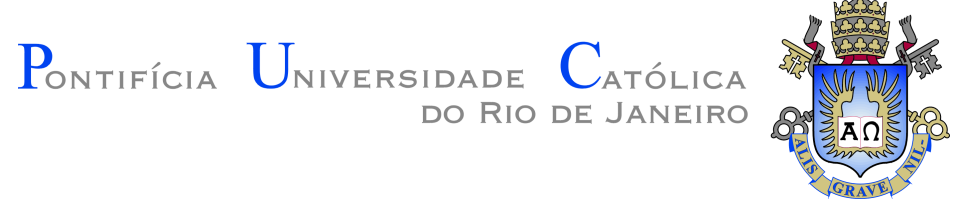

Roberto Simonelli Lee

\section{Productive and Allocative Efficiency of State Owned Enterprises: Evidence from the Brazilian Privatization Program}

Dissertation presented to the Programa de Pós-graduação em Economia da PUC-Rio in partial fulfillment of the requirements for the degree of Mestre em Economia. Approved by the Examination Committee.

Prof. Leonardo Rezende

Advisor

Departamento de Economia - PUC-Rio

Prof. Gustavo Gonzaga

Co-advisor

Departamento de Economia - PUC-Rio

Prof. Daniel Veloso Chaves

Departamento de Economia - University of Western Ontario

Prof. Pedro Cavalcanti Ferreira

Fundação Getúlio Vargas - EPGE

Rio de Janeiro, June the 19th, 2020 
All rights reserved.

\section{Roberto Simonelli Lee}

B.A. in Economics, University of Sao Paulo (USP-SP), 2015.

Bibliographic data

Simonelli Lee, Roberto

Productive and Allocative Efficiency of State Owned Enterprises: Evidence from the Brazilian Privatization Program / Roberto Simonelli Lee ; advisor: Leonardo Rezende; coadvisor: Gustavo Gonzaga. - Rio de janeiro: PUC-Rio, Departamento de Economia , 2020.

v., 53 f: il. color. ; $30 \mathrm{~cm}$

Dissertação (mestrado) - Pontifícia Universidade Católica do Rio de Janeiro, Departamento de Economia .

Inclui bibliografia

1. Economia - Teses. 2. Organização Industrial - Teses. 3. Empresas Estatais;. 4. Produtividade;. 5. Privatização. I. Rezende, Leonardo. II. Gonzaga, Gustavo. III. Pontifícia Universidade Católica do Rio de Janeiro. Departamento de Economia. IV. Título. 


\section{Acknowledgments}

I would like to thank my advisors Prof. Leonardo Rezende and Prof. Gustavo Gonzaga, whose insightful comments and contributions were essential to this research. I also thank professors Pedro Cavalcanti Ferreira and Daniel Chaves for helpful comments and critiques. Any mistakes are my own.

I thank IBGE for granting me access to the PIA microdata as well as fellow researchers at Sala de Sigilo for helping me navigate through this dataset. I also thank the Brazilian Ministry of Labor, which, through the Programa de Disseminação de Estatísticas do Trabalho, has granted PUC-Rio to the information collected by RAIS. This research would not have been possible without their help.

I am thankful to my family and friends, especially Erica, for the support and camaraderie.

This study was financed in part by the Coordenação de Aperfeiçoamento de Pessoal de Nível Superior - Brasil (CAPES) - Finance Code 001. We also gratefully acknowledge funding from PUC-Rio and FAPERJ. 


\section{Abstract}

Simonelli Lee, Roberto; Rezende, Leonardo (Advisor); Gonzaga, Gustavo (Co-Advisor). Productive and Allocative Efficiency of State Owned Enterprises: Evidence from the Brazilian Privatization Program. Rio de Janeiro, 2020. 53p. Dissertação de mestrado - Departamento de Economia , Pontifícia Universidade Católica do Rio de Janeiro.

In the early 1990s, the Brazilian government carried out one of the largest privatization programs in the world. With microdata on Brazilian firms, we study whether privatization has reduced the costs of production of State-Owned Enterprises (SOEs). Past literature has assessed whether privatization has increased firms' total factor productivity (TFP). We argue that privatization could impact the costs of production by another mechanism besides TFP: SOEs may exhibit distortions that prevent them from choosing the cost-minimizing mix of inputs, and privatization may mitigate these distortions. By estimating the production function, we can not only estimate the TFP of firms but also write the first-order conditions of the cost minimization problem and obtain a measure of these distortions. Our results suggest firms enhance their TFP following privatization and make better allocations of capital. According to our results, in the long run, the improvement in the allocation decision accounts for $14.37 \%$ of the cost reduction after privatization.

\section{Keywords}

State Owned Enterprises Productivity; Privatization. 


\section{Resumo}

Simonelli Lee, Roberto; Rezende, Leonardo; Gonzaga, Gustavo. Eficiência produtiva e alocativa de Empresas Estatais: Evidências do programa de privatizações brasileiro. Rio de Janeiro, 2020. 53p. Dissertação de Mestrado - Departamento de Economia , Pontifícia Universidade Católica do Rio de Janeiro.

No início dos anos 1990, o governo brasileiro executou um dos maiores programas de privatização no mundo. Com microdados de firmas brasileiras, nós estudamos se a privatização levou a uma redução nos custos de produção das empresas estatais. A literatura passada avaliou se a privatização levou a um aumento na produtividade total dos fatores (PTF). Nós argumentamos que a privatização pode afetar os custos de produção por outro mecanismo além da PTF: as estatais podem sofrer distorções que as impedem de escolher a cesta de insumos que minimiza custo, e a privatização pode mitigar essas distorções. Ao estimar a função de produção, nós podemos não apenas estimar a PTF, mas também podemos escrever as condições de primeira ordem do problema de minimização de custos e obter uma medida dessas distorções. Nossos resultados sugerem que as empresas aumentam sua PTF após a privatização e fazem melhores alocações de capital. De acordo com nossos resultados, no longo prazo, a melhora nas decisões de alocação responde por $14.37 \%$ da redução de custo após a privatização.

\section{Palavras-chave}

Empresas Estatais; Produtividade; Privatização 


\section{Table of contents}

1 Introduction $\quad 10$

1.1 Related Literature 11

2 Data 13

2.1 Institutional Background 13

2.2 Data 13

3 Methodology and Production Function Estimates 17

$\begin{array}{lll}3.1 & \text { Allocative Efficiency } & 17\end{array}$

$\begin{array}{ll}\text { 3.2 Production Function Estimation } & 19\end{array}$

3.3 Outcome Variables Construction 21

3.4 Data on product and inputs 22

3.5 Production Function Estimates 22

4 Empirical Strategy and Results $\quad \mathbf{2 6}$

$\begin{array}{lll}4.1 & \text { Empirical Strategy } & 26\end{array}$

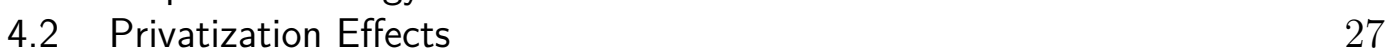

4.2.1 Testing Parallel Trends 27

$\begin{array}{ll}\text { 4.2.2 Estimated effects } & 29\end{array}$

$\begin{array}{lll}4.3 & \text { Discussion } & 33\end{array}$

4.4 Economic Significance $\quad 35$

$\begin{array}{lll}4.5 & \text { Robustness Checks } & 38\end{array}$

5 Conclusions $\quad 45$

6 Appendix $\quad 48$

6.1 Dealing with the noise in Legal Nature data 48

6.2 Production Function Estimation and Variables used 48

6.3 Wedges under GNR assumptions 50

6.4 Weighted Regressions $\quad 51$ 


\section{List of tables}

Table 2.1 Descriptive Statistics by group of Brazilian Manufacturing Firms in 1996

Table 3.1 Estimates of production function: OLS and FE methodologies

Table 3.2 Descriptive statistics of elasticities estimated using the GNR framework in 1996

Table 3.3 Descriptive Statistics of variables obtained with the GNR estimates

Table 4.1 Estimates of equations 4-9 and 4-10 


\section{List of Abreviations}

RAIS - Registro Anual de Informação Social

PIA - Pesquisa Industrial Anual

CNPJ - Cadastro Nacional da Pessoa Jurídica

CNAE - Classificação Nacional de Atividades Econômicas

FOC - First Order Conditions

PND - Plano Nacional de Desestatização

SOE - State-Owned Enterprises

TFP - Total Factor Productivity 


\section{Introduction}

In the early 1990s, Brazil carried out one of the largest privatization programs in the world. This paper uses this program to test whether privatization has affected the efficiency of State-Owned Enterprises (SOE).

We understand efficiency in the following sense: a more efficient firm is able to produce the same amount of output while incurring lower costs. In this sense, total factor productivity (TFP) is one (and perhaps the most important) element that explains firms' efficiency. Brown et al. (2006) and Chen et al. (2018), thus, study whether privatization has increased TFP of SOEs. We argue that if we focus solely on TFP, we are not fully exploring the economics of this problem. Besides TFP channel, there may also be other mechanisms that explains how privatization could lower the costs of production. Firms choose inputs to minimize these costs. However, there could be distortions that prevent SOEs from doing so. For example, agency problems may lead SOEs to hire more workers (or pay higher wages) than the optimal amount; difficulties with bureaucracy may raise the capital's adjustment costs of SOEs. While TFP measures whether firms are using their inputs in the most efficient ways or are able to select the most cost-effective inputs, it does not capture these allocative distortions across inputs.

In the spirit of Hsieh and Klenow (2009) and Petrin and Sivadasan (2013), once we estimate the production function, we can not only estimate TFP, but we can also measure the distance between the theoretical optimal (cost-minimizing) allocation of inputs and the observed input allocation of firms. Thus, our contribution is to test the impact of privatization not only on TFP (or productive efficiency) but also on the allocative efficiency of firms, i.e., choosing a mix of inputs that is more in line with the cost minimization problem.

Our empirical framework is the Brazilian privatization program (or Plano Nacional de Desestatização - PND). There are three advantages to this empirical scenario. The first is the fact that this was one of the largest privatization programs in the world, encompassing multiple sectors of the economy. Another advantage is that Brazil displays very detailed data on firms. Since 1995, RAIS (Relação Anual de Informações Sociais) collects 
information regarding the legal nature of firms. We can use this data to identify which firms are SOEs in a given year, which allows us to identify the instances of privatization. Moreover, since 1996, PIA (Pesquisa Industrial Anual), administered by the Instituto Brasileiro de Geografia e Estatística (IBGE), collects information at the firm level of value of output and input usage, which allows us to estimate the production function. A third advantage is that the PND provides credible exogenous variation to assess the impact of privatization as we will clarify below.

We discuss an alternative interpretation after we present the results in chapter 4 .

Our results show that firms improve both of their allocative and productive efficiencies following privatization. However, the improvement in allocative efficiency seems to concentrate on the allocation of capital, with the allocative efficiency of labor being little affected. In the long run, the improvement in allocative efficiency accounts for $14.37 \%$ of the reduction in cost following privatization.

\section{1 \\ Related Literature}

Our paper relates to the literature that discusses the determinants of TFP reviewed by Syverson (2011). More specifically, we explore how state ownership can affect firm TFP. Brown et al. (2006) estimate these effects using data on four countries of the former USSR, Russia, Romania, Ukraine, and Hungary. They reach mixed results in their analysis: while they find that privatization positively impacted TFP of Romanian, Hungarian and Ukrainian SOEs, they also find a negative impact on Russian SOEs. A more recent study on this topic is found in Chen et al. (2018). These authors study the effects of privatization on Chinese firms and find that privatization had a positive impact on TFP. This effect, however, seems to be heterogeneous across different firm sizes: while the effect seems to be great for small and medium enterprises, the productivity gap between SOEs and private firms is negligible across the largest enterprises.

This paper also relates to a growing literature that estimates wedges in the first-order conditions (FOC) of one problem of the firm and gives some economic interpretation of these wedges. For example, De Loecker and Warzynski (2012), Brandt et al. (2017), De Loecker et al. (2016) and De Loecker and Eeckhout (2017), estimate a wedge on the first-order condition on the problem of cost minimization and interpret it as markups. Most of these studies assess the effects of international trade on firms' markups.

We use the same intuition of the literature cited above to estimate wedges 
on input choice in a model very similar to Hsieh and Klenow (2009). They use a model where there are wedges on firms' perceived price of their output, and the perceived price of capital ${ }^{1}$. In their framework, these distortions imply that resources will be poorly allocated across firms. Their model is interested in estimating the effect of these wedges on misallocation across firms that dampen the TFP of the economy as a whole. The estimation relies on two assumptions (technology exhibits constant returns to scale and preferences have constant elasticity of substitution), which have been criticized by recent literature, see Haltiwanger et al. (2018). Despite the importance of these questions, we will not have anything to say about misallocation. Our goal is to test whether SOEs choose a mix of inputs that is more in line with the cost minimization problem. Thus, our model precludes assumptions on returns to scale and on consumer preferences.

The most similar model that we could find to ours is Petrin and Sivadasan (2013), which proposes a method to estimate the loss of output due to distortions in allocation. Their methodology relies on the difference between the value of an input's marginal product (i.e., the price of the output times the marginal product of a given input) with this input's price. Since we do not have access to information on prices, our framework can only rely on information about the value of the inputs used by a given firm.

Our paper also relates to the literature that studies the Brazilian privatization program. As Megginson and Netter (2001) puts it, given the size of the Brazilian economy and its privatization program, "this country's program is likely to remain very influential". However, this literature is surprisingly scarce; Anuatti-Neto et al. (2003) study the effects of privatization on various measures of efficiency using panel analysis. More recent research can be found in Arnold (2018), who studies the impact of privatization on wages of workers.

This dissertation is organized as follows: Chapter 2 discusses the institutional background and the data; chapter 3 exposes the methodology employed to estimate the allocative efficiency of firms as well as their TFP; chapter 4 presents the results; the final chapter concludes.

\footnotetext{
${ }^{1}$ The first type of distortions is what De Loecker and Warzynski (2012) estimates as markups, while the latter is what we estimate in this paper
} 


\section{Data}

\section{1}

\section{Institutional Background}

In Brazil, since the 1930s, the State viewed SOEs as a crucial instrument for its development policies and invested heavily, but not exclusively, in industries that it deemed strategical. Although this investment was not consistently implemented over time, by the 1980s, SOEs were numerous and widespread across the sectors of the economy, with about two hundred firms owned by the federal government and thousands owned by states and municipalities.

During the second half of the 1970s, due to difficulties in obtaining long term financing, the federal government financed its investments with resources backed by external loans that were taken by SOEs. Therefore, by the 1980s, these firms had large amounts of debt.

In the late 1980s, the government was also dealing with a fiscal crisis, and privatization was seen, in the early 1990s, as a key policy in financial adjustment: it could not only quickly gather large amounts of revenue, but it could also transfer a significant proportion of its debt to private hands. In 1991, the government started the Brazilian Privatization Program (PND). However, it was only after 1996, when other programs were implemented to privatize SOEs owned by state and municipal governments and SOEs in the telecommunications sector, that most of the privatizations were executed. Estimates from Anuatti-Neto et al. (2003) indicate that $69 \%$ of the total value as of July 2001 was privatized in the years of 1997 and 1998.

\section{2}

Data

Our data covers microdata on firms from 1996 to 2016. This allows us to assess the effects of privatizations that happened in or after 1997 but before 2016 .

We rely on two databases. The first one is RAIS, which was administered by the Ministry of Labor and Employment, and is now administered by the Ministry of the Economy. RAIS annually collects microdata on the contract 


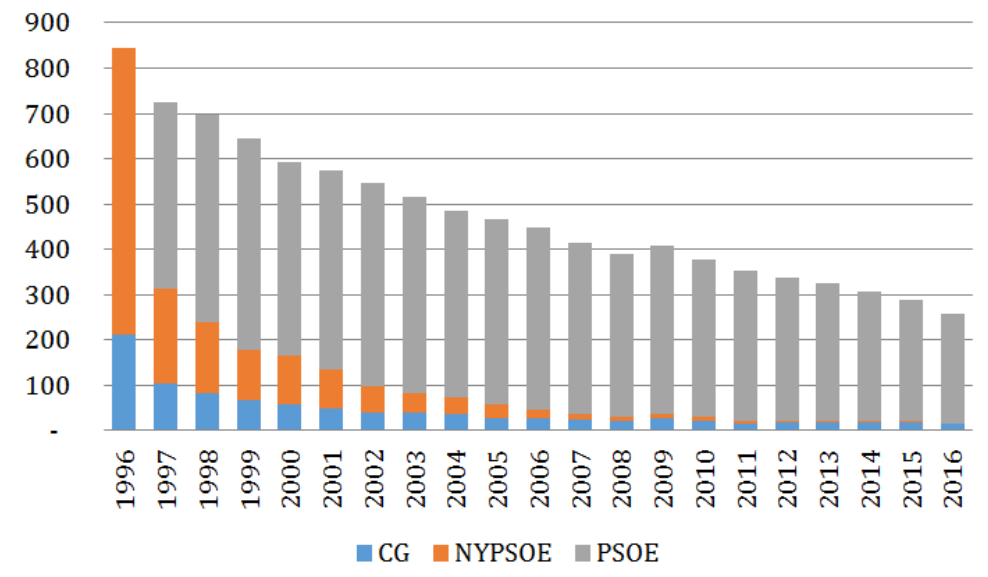

Figure 2.1: Number of firms by group over time.

level of all labor contracts in the country. Since 1995, it also collects information on the legal nature of the establishments in Brazil. We can use this information to identify which firms are State-owned and which ones are private in a given year ${ }^{1}$. Since RAIS displays information of the Cadastro Nacional de Pessoa Jurídica (CNPJ) of the establishments, we can follow the legal nature of firms throughout the years: from 1995 to 2017 (which is the most recent information we have). We define an instance of privatization in year $t$ if the legal nature of the head office of the firm indicates that the firm is private but in $t-1$ it indicates that it is an SOE. We should, however, point out that this information is quite noisy since it is self-reported. In the appendix, we describe the adjustments we implemented in the data so we could eliminate false positives.

The second database is the Pesquisa da Indústria Anual (PIA) which is supervised by IBGE. PIA has annual information at the firm level of the value of output produced and inputs used by the firm. PIA studies every firm in the manufacturing sector with at least 30 employees. Although this data is classified, IBGE allows researchers to access it inside its controlled facilities ${ }^{2}$.

For the following graphs and tables, we will refer to four groups of firms: Private firms, denoted by the letter P; SOEs that were privatized during our sample period but were still not privatized at a given year, denoted by NYPSOE (for "not yet privatized SOE"); Privatized SOE, denoted by PSOE; and SOEs that were not privatized in our sample period, denoted by CG ("control group").

In Figure 2.1, we describe our sample. First, we note that almost all SOEs in the manufacturing sector was privatized during 1997 and 2016. Also,

\footnotetext{
${ }^{1} 3$ codes show which establishments are SOEs: 201-1, 203-8 and 205-4.

${ }^{2}$ To report statistics, researchers ask the permission of IBGE, which checks whether the statistics do not violate rules of confidentiality.
} 
as time goes on, firms leave our sample. This could be due to three reasons: some firms may have stopped meeting the requirements to be studied by PIA; some firms may have changed their CNPJ; some firms may have exited the market. With the available data, we can not identify which of these reasons explain why we no longer have information on each of these firms.

Table 2.1 presents some descriptive statistics of the different groups of firms in 1996. What these statistics show is that the largest and smallest SOEs were less likely to participate in the PND. 
Table 2.1: Descriptive Statistics by group of Brazilian Manufacturing Firms in 1996

\begin{tabular}{|c|c|c|c|}
\hline & NYPSOE & CG & $\mathrm{P}$ \\
\hline & \multicolumn{3}{|c|}{ Number of Workers } \\
\hline Mean & 121.6 & 297.3 & 136.1 \\
\hline Standard Deviation & 640.1 & 2994 & 514 \\
\hline $1^{\text {st }}$ percentile & 5 & 1 & 2 \\
\hline $5^{\text {th }}$ percentile & 7 & 3 & 5 \\
\hline $10^{t h}$ percentile & 12 & 5 & 7 \\
\hline $25^{t h}$ percentile & 32 & 12 & 20 \\
\hline $50^{t h}$ percentile & 50 & 29 & 44 \\
\hline $75^{\text {th }}$ percentile & 87 & 85 & 97 \\
\hline $90^{t h}$ percentile & 206 & 218 & 252 \\
\hline $95^{\text {th }}$ percentile & 324 & 425 & 479 \\
\hline $99^{\text {th }}$ percentile & 930 & 1586 & 1650 \\
\hline \multirow[t]{2}{*}{ Observations } & 633 & 211 & 29590 \\
\hline & \multicolumn{3}{|c|}{ Value of inputs (in million Reais) } \\
\hline Mean & 765.78 & 3585.38 & 187.12 \\
\hline Standard Deviation & 17713.81 & 50828.84 & 1648.36 \\
\hline $1^{\text {st }}$ percentile & 0.11 & 0.05 & 0.06 \\
\hline $5^{\text {th }}$ percentile & 0.39 & 0.11 & 0.19 \\
\hline $10^{t h}$ percentile & 0.86 & 0.22 & 0.38 \\
\hline $25^{\text {th }}$ percentile & 3.68 & 0.71 & 1.77 \\
\hline $50^{\text {th }}$ percentile & 10.89 & 4.49 & 8.56 \\
\hline $75^{\text {th }}$ percentile & 38.81 & 17.89 & 38.79 \\
\hline $90^{t h}$ percentile & 106.14 & 63.2 & 182.81 \\
\hline $95^{\text {th }}$ percentile & 237.08 & 142.02 & 510.54 \\
\hline $99^{\text {th }}$ percentile & 1218.17 & 1308.87 & 3175.41 \\
\hline \multirow[t]{2}{*}{ Observations } & 632 & 206 & 29301 \\
\hline & \multicolumn{3}{|c|}{ Value of Product (in million Reais) } \\
\hline Mean & 30.38 & 266.62 & 35.02 \\
\hline Standard Deviation & 268.62 & 3694.79 & 275.18 \\
\hline $1^{\text {st }}$ percentile & 0.1 & 0.03 & 0.04 \\
\hline $5^{\text {th }}$ percentile & 0.26 & 0.1 & 0.14 \\
\hline $10^{t h}$ percentile & 0.5 & 0.16 & 0.27 \\
\hline $25^{\text {th }}$ percentile & 1.79 & 0.38 & 0.98 \\
\hline $50^{\text {th }}$ percentile & 4.47 & 1.84 & 3.57 \\
\hline $75^{\text {th }}$ percentile & 11.31 & 7.46 & 12.58 \\
\hline $90^{\text {th }}$ percentile & 34.73 & 19 & 48.3 \\
\hline $95^{\text {th }}$ percentile & 58.34 & 55.07 & 113.36 \\
\hline $99^{\text {th }}$ percentile & 367.42 & 364.64 & 539.91 \\
\hline Observations & 633 & 211 & 29590 \\
\hline
\end{tabular}

Notes: Product and cost values deflated to 2016 Reais using IPCA 


\section{3}

\section{Methodology and Production Function Estimates}

In this chapter, we explain how we construct our main variables of interests, namely, TFP and allocative efficiency. We assess the effect of privatization in these variables in Chapter 4.

\section{1}

\section{Allocative Efficiency}

Our main methodological contribution is the construction of the allocative efficiency measure. Let $Y_{t}\left(M_{j t}, K_{j t}, L_{j t}\right)$ denote the amount of output in year $t$ produced by firm $j$ when it uses $M_{j t}, K_{j t}$ and $L_{j t}$ levels of intermediate goods, capital and labor respectively.

Let $P_{t}^{M}, w_{t}$, and $r_{t}$ denote the prices of intermediate goods, wages and the rents paid to capital. To minimize costs, firms should solve:

$$
\begin{array}{r}
\operatorname{Min}_{K_{j t}, L_{j t}, M_{j t}} w_{j t} L_{j t}+r_{j t} K_{j t}+P_{j t}^{M} M_{j t} \\
\text { s.t. } Y\left(K_{j t}, L_{j t}, M_{j t}\right) \geq \bar{Y}_{j t}
\end{array}
$$

However, distortions may impede firms from reaching the optimum of this problem. As Hsieh and Klenow (2009) suggest $^{1}$, one way to model these distortions is imposing a wedge on the price of inputs, as such:

$$
\begin{array}{r}
\operatorname{Min}_{K_{j t}, L_{j t}, M_{j t}} \tau_{j t}^{L} w_{j t} L_{j t}+\tau_{j t}^{K} r_{j t} K_{j t}+P_{j t}^{M} M_{j t} \\
\text { s.t. } Y\left(K_{j t}, L_{j t}, M_{j t}\right) \geq \bar{Y}_{j t}
\end{array}
$$

Once we write the lagrangian of this problem, equation 3-3, we get the FOC

${ }^{1}$ In their paper, they impose wedges on the profit maximization problem as such:

$$
\operatorname{Max}_{K_{j t}, L_{j t}} \tau_{j t}^{Y} P_{j t}^{Y} Y\left(L_{j t}, K_{j t}\right)-w_{j t} L_{j t}-\tau_{j t}^{k} r_{j t} K_{j t}
$$

where $P_{j t}^{Y}$ is the price of the output of the firm. 
described in equations $3-4$

$$
\begin{gathered}
\mathcal{L}=P_{t}^{M} M_{j t}+\tau_{j t}^{L} w_{t} L_{j t}+\tau_{j t}^{K} r_{t} K_{j t}+\mu\left(\bar{Y}_{j t}-Y\left(M_{j t}, K_{j t}, L_{j t}\right)\right) \\
\mu \frac{\partial Y}{\partial M}=P_{t}^{M} \\
\mu \frac{\partial Y}{\partial K}=\tau_{j t}^{K} r_{t} \\
\mu \frac{\partial Y}{\partial L}=\tau_{j t}^{L} w_{t}
\end{gathered}
$$

Where $\mu$ is the Lagrangian multiplier, $\bar{Y}_{j t}$ the minimum output imposed by the restriction. If we denote the elasticities of labor, capital and intermediate goods as $\theta_{t}^{L}\left(M_{j t}, K_{j t}, L_{j t}\right), \theta_{t}^{K}\left(M_{j t}, K_{j t}, L_{j t}\right)$ and $\theta_{t}^{M}\left(M_{j t}, K_{j t}, L_{j t}\right)$, with simple manipulations, we get:

$$
\begin{aligned}
\tau_{j t}^{K} & =\frac{\theta_{t}^{K}(\cdot)}{\theta_{t}^{M}(\cdot)} \frac{P_{t}^{M} M_{j t}}{r_{t} K_{j t}} \\
\tau_{j t}^{L} & =\frac{\theta_{t}^{L}(\cdot)}{\theta_{t}^{M}(\cdot)} \frac{P_{t}^{M} M_{j t}}{w_{t} L_{j t}}
\end{aligned}
$$

The wedges $\tau$ essentially capture distortions in the perception of inputs' prices, i.e., even though prices are given by $w_{j t}$ and $r_{j t}$, the firm behaves as if it were minimizing costs with perceived prices of $\tau_{j t}^{L} w_{j t}$ and $\tau_{j t}^{K} r_{j t}$. This distortion of perceived prices could be explained by multiple factors: costs of adjustments, poor management skills, unexpected shocks to the price of inputs, market power, etc. If, for example, unexpected shocks lead firms to operate with idle capital, in the data we should observe $\tau_{j t}^{K}$ lower than 1 , i.e., hiring more capital than the optimal amount. Credit constraints, on the other hand, which could coerce firms to operate with levels of capital lower than the optimum, should raise $\tau_{j t}^{L}$. In a frictionless world, we should observe $\tau^{k}=\tau^{L}=1$. Of course, since a lot of factors are working simultaneously to distort prices, it is not so clear what to expect of the levels of $\tau$. We do not have a method that can separate how each factor affects the wedges computed. Our question, thus, is simply whether privatization helps to minimize distortions by bringing these wedges closer to 1 .

One important remark is that since these wedges are calculated from the cost minimization problem, they are robust to a number of different assumptions regarding the structure of competition of firms. We will, however, assume perfect competition in order to identify the production function as in Gandhi et al. (2018).

We also assume that firms have no distortions in observing the price of intermediate goods. If this should be the case, our estimates of $\tau^{L}$ and $\tau^{K}$ 
would measure the distortions in the price of labor and capital relative to the distortions in the price of intermediate goods.

Hsieh and Klenow's model aims to answer a macroeconomic question: can the economy's resources be redistributed across firms in such a way that the productivity of the entire economy increases? To answer this question, their methodology relies on two key assumptions: the functional form of demand follows a Constant Elasticity of Substitution (CES), and technology exhibits constant returns to scale. Their model has been criticized by Haltiwanger et al. (2018), who show that their measure of misallocation is sensitive to model misspecification. However, our question is whether distortions in input choice are attenuated by privatization. Thus, we preclude assumptions regarding demand structure and returns to scale. Therefore, the wedges of our model are robust to different specifications about demand and technology.

\section{2}

\section{Production Function Estimation}

We estimate the production function relying on Gandhi et al. (2018) (GNR, henceforth), who propose a method that identifies non parametrically the production function from the FOC of the profit maximization problem. We provide the details of the estimation procedure in the appendix.

The GNR model is based on three key assumptions: firms are price takers; they maximize profits; intermediate goods are flexible goods and labor and capital are quasi-fixed inputs. In other words, in a given period $t$, firms take the amount of labor and capital as given, but choose the amount of intermediate consumption used in $t$ to maximize their profits. Further, they choose labor and capital for the following period $t+1$. An important observation is that the model does not impose further assumptions on how firms choose capital and labor. This is particularly useful for us since we will impose no restrictions on the allocative efficiency measures of labor $\tau^{L}$ and capital $\tau^{K}$. Another important reason why we use GNR is that their framework identifies the gross production function and is able to estimate the elasticities of materials, thereby, we can estimate the wedges with respect to both labor and capital.

One criticism that could be made to our methodology is that we are assuming that firms choose $M_{j t}, L_{j t}, K_{j t}$ to minimize costs to estimate $\tau$, whereas in the estimation procedure, we assume that the firm chooses $L_{j t+1}, K_{j t+1}$ in $t$. In the appendix, we show that we can arrive at the same expressions as in 3-5 and 3-6 with the same assumptions made in GNR. We chose to present the model with capital and labor as flexible inputs as well since it provides a clearer intuition of what these wedges are capturing. 
Another line of questioning could be that, as we have stated, there may be distortions that impede SOEs from minimizing costs. Thus, relying on GNR, which assumes firms maximize profits, might not be ideal. Our assumption, however, is that when choosing intermediate consumption, SOEs do not face any distortions.

The production function is given by:

$$
Y_{j t}=F\left(K_{j t}, L_{j t}, M_{j t}\right) \exp \left(\omega_{j t}+\varepsilon_{j t}\right)
$$

where, $Y_{j t}, K_{j t}, L_{j t}$ and $M_{j t}$ stands for output produced, capital, labor and intermediate goods used by firm $j$ in year $t . \omega_{j t}$ is the TFP of firm $j$ in time $t$ and $\varepsilon_{j t}$ are i.i.d. shocks in the productivity of firms that is not known to the firm at time $t$. If we take the log of equation 3-7, and write $y_{j t}, k_{j t}, l_{j t}$ and $m_{j t}$ as the logs of $Y_{j t}, K_{j t}, L_{j t}$ and $M_{j t}$, we get

$$
y_{j t}=f\left(k_{j t}, l_{j t}, m_{j t}\right)+\omega_{j t}+\varepsilon_{j t}
$$

For our estimation, we assume ${ }^{2}$

$$
\begin{aligned}
f(\cdot)= & \left(\begin{array}{c}
\gamma_{0}+\gamma_{k} k_{j t}+\gamma_{l} l_{j t}+\frac{\gamma_{m}}{2} m_{j t}+\gamma_{k k} k_{j t}^{2}+\gamma_{l l} l_{j t}^{2} \\
+\frac{\gamma_{m m}}{3} m_{j t}^{2}+\gamma_{k l} k_{j t} l_{j t}+\frac{\gamma_{k m}}{2} k_{j t} m_{j t}+\frac{\gamma_{l m}}{2} l_{j t} m_{j t}
\end{array}\right) m_{j t} \\
& +\beta_{l} l_{j t}+\beta_{k} k_{j t}+\beta_{l l} l_{j t}^{2}+\beta_{k k} k_{j t}^{2}+\beta_{l k} l_{j t} k_{j t}
\end{aligned}
$$

We denote the elasticities of intermediate goods, capital, and labor on output respectively as $\theta^{M}, \theta^{K}, \theta^{L}$. GNR show that we can identify (and estimate) $\theta^{M}$ and $\varepsilon$ from the following equation:

$$
\log \left(\frac{P_{t}^{M} M_{j t}}{P_{j t}^{Y} Y_{j t}}\right)=\log \left(\theta^{M}\left(K_{j t}, L_{j t}, M_{j t}\right)\right)+\log \left(\mathbb{E}\left(\exp \left(\varepsilon_{j t}\right)\right)\right)-\varepsilon_{j t}
$$

Where $P_{t}^{Y}$ is the price of the output of the firm.

By the Fundamental Theorem of Calculus,

$$
\int \frac{\theta^{M}\left(L_{j t}, K_{j t}, M_{j t}\right)}{M_{j t}} d M_{j t}=\log F\left(L_{j t}, K_{j t}, M_{j t}\right)-C\left(L_{j t}, K_{j t}\right)
$$

From equation 3-10, we can write:

$$
y_{j t}-\int \frac{\theta^{M}\left(L_{j t}, K_{j t}, M_{j t}\right)}{M_{j t}} d M_{j t}-\varepsilon_{j t}=C\left(L_{j t}, K_{j t}\right)+\omega_{j t}
$$

We define the left-hand side of equation 3-11 as $\mathcal{Y}_{j t}$ which is an observable random variable since it is constructed from identifiable variables from the data. As in Olley and Pakes (1996), we can then identify the remaining

${ }^{2}$ This is the same as approximating $\theta^{M}(\cdot)$ in equation $3-9$ and $C(\cdot)$ in equation 3-10 by second degree polynomials 
parameters of the production function, if we impose that $\omega_{j t}$ follows some stochastic process. Here we make some slight alterations in GNR.

In GNR, it is assumed that $\omega_{j t}$ follows a Markov process. We impose the following: we assume

$$
\begin{aligned}
\mathbb{E}\left[\omega_{j ; t+1} \mid \mathcal{I}_{j t}\right] & =\mathbb{E}\left[\omega_{j ; t+1} \mid \omega_{j t} ; t+1 ; S O E_{j t+1}\right] \\
& =\lambda_{t+1}+h\left(\omega_{j t}, S O E_{j t+1}\right)
\end{aligned}
$$

where $\mathcal{I}_{j t}$ is the set of all information known to firm $j$ in time $t$ and $S O E_{j ; t+1}$ is an indicator of whether a firm is an SOE. Parameter $\lambda_{t+1}$, which is common to all firms, implies that managers, when they predict their TFP in the following year, take into account how the entire economy will perform in the next year, and this prediction is common to all managers. We also assume that the expected TFP is a function of whether the firm is an SOE in the next period or not. We do this since what we want to test is whether the TFP of private firms and SOEs are systematically different, so we let the TFP of private firms and SOE be realizations from random variables that have different distributions.

The assumptions above imply that:

$$
\omega_{j t}=\lambda_{t}+h\left(\omega_{j t-1}, S O E_{j t}\right)+\eta_{j t}
$$

where $\eta_{j t}$ is a variable that is orthogonal to any variable in the information set of firm $j$ in $t-1$, in particular, it is orthogonal to any function of the decisions taken by the firm in $t-1$, i.e., $k_{j t}$ and $l_{j t} . h(\cdot)$ is a non parametric function. And since $\omega_{j t}=\mathcal{Y}_{j t}-C\left(L_{j t}, K_{j t}\right)$, we can write:

$$
\mathcal{Y}_{j t}-C\left(L_{j t}, K_{j t}\right)=\lambda_{t}+h\left(\mathcal{Y}_{j ; t-1}-C\left(L_{j t-1}, K_{j t-1}\right)\right)+\eta_{j t}
$$

which identifies $h . C\left(L_{j t}, K_{j t}\right)$ is identified in the following equation:

$$
\mathcal{Y}_{j t}=C\left(L_{j t}, K_{j t}\right)+\lambda_{t}+h\left(\mathcal{Y}_{j ; t-1}-C\left(L_{j t-1}, K_{j t-1}\right)\right)+\eta_{j t}
$$

We estimate $h$ and $C\left(L_{j t}, K_{j t}\right)$ using the following moment conditions:

$$
\mathrm{E}\left[\begin{array}{llllll}
\eta_{i t}(1 & l_{i t} & k_{i t} & l_{i t}^{2} & k_{i t}^{2} & \left.l_{i t} k_{i t}\right)^{\prime}
\end{array}\right]=0
$$

\section{3}

\section{Outcome Variables Construction}

We are interested in assessing the effect of privatization on two measures of efficiency, namely TFP and allocative efficiency.

As is typical in the literature, TFP, or $\omega_{j t}$ in our model, is obtained as 
the residual

$$
\hat{\omega}_{j t}=y_{j t}-\hat{f}\left(m_{j t}, l_{j t}, k_{j t}\right)-\hat{\varepsilon}_{j t}
$$

We, then, estimate the wedges as:

$$
\begin{aligned}
\hat{\tau}_{j t}^{K} & =\frac{\hat{\theta}_{t}^{K}(\cdot)}{\hat{\theta}_{t}^{M}(\cdot)} \frac{P_{t}^{M} M_{j t}}{r_{t} K_{j t}} \\
\hat{\tau}_{j t}^{L} & =\frac{\hat{\theta}_{t}^{L}(\cdot)}{\hat{\theta}_{t}^{M}(\cdot)} \frac{P_{t}^{M} M_{j t}}{w_{t} L_{j t}}
\end{aligned}
$$

\section{4}

\section{Data on product and inputs}

Our data do not allow us to observe quantities produced and, thus, we are forced to treat quantities $Y_{j t}$ as being equal to product value $P_{j t}^{Y} Y_{j t}$. Since we do this, $\omega_{j t}$ captures what is called in the literature as Total Factor Productivity in Revenue (TFPR). As we see, this is not a drawback in our framework but an advantage. Once a firm becomes more efficient, it could opt to increase the quality of their good, which could enable it to sell its product at a higher price. TFPR captures this effect. If we were able to treat quantities produced and value produced as separate elements, $\omega$ would not capture this effect.

We observe the number of workers $L_{j t}$ each firm employs and the total costs with employees $w_{j t} L_{j t}$. However, we are not able to do the same for capital and intermediate consumption.

Intermediate consumption is measured as the sum of materials used in production, costs associated with energy, and service provided by other firms ${ }^{3}$.

We construct the capital stock series with the perpetual inventory method taking the depreciation as $5 \% 4$.

\section{5}

\section{Production Function Estimates}

Before discussing our results, we first estimate alternative methodologies of the production function, so as to compare with the GNR method. We regress the following:

$$
\begin{gathered}
y_{j t}=\theta_{O L S}^{L} L_{j t}+\theta_{O L S}^{K} K_{j t}+\theta_{O L S}^{M} M_{j t}+\omega_{j t}^{O L S} \\
y_{j t}=\alpha_{j}+\theta_{F E}^{L} L_{j t}+\theta_{F E}^{K} K_{j t}+\theta_{F E}^{M} M_{j t}+\omega_{j t}^{F E}
\end{gathered}
$$

${ }^{3}$ The variables collected by IBGE that were used are presented in the appendix ${ }^{4}$ More details on the appendix 
Table 3.1 shows the results. These methodologies are known to be problematic. As argued by Griliches and Mairesse (1995), equations 3-20 is endogenous and tends to overestimate the production function elasticities. Equation 321 corrects this endogeneity issue, but its problem is practical: it amplifies measurement errors, and typically result in underestimated elasticities. As it turns out, this appears to be the case in our exercise. We can see that according to the OLS methodology, Brazilian firms have increasing returns to scale, while, according to the FE approach, they have decreasing returns to scale.

Table 3.1: Estimates of production function: OLS and FE methodologies

\begin{tabular}{lrr}
\hline & OLS & $\mathrm{FE}$ \\
& $\mathrm{y}_{j t}$ & $\mathrm{y}_{j t}$ \\
\hline$\theta^{K}$ & $0.285^{* * *}$ & $0.0640^{* * *}$ \\
& $(0.000662)$ & $(0.000996)$ \\
$\theta^{M}$ & $0.719^{* * *}$ & $0.396^{* * *}$ \\
& $(0.000676)$ & $(0.000609)$ \\
$\theta^{L}$ & $0.169^{* * *}$ & $0.433^{* * *}$ \\
& $(0.00125)$ & $(0.00111)$ \\
& & \\
\hline Observations & 793,526 & 793,526 \\
R-squared & 0.996 & 0.963 \\
\hline
\end{tabular}

Standard errors in parentheses. Statistical significance at $10 \%, 5 \%$ and $1 \%$ is indicated by $*, * *$ and ${ }^{* * *}$ respectively

We then employ the GNR method to estimate the production function. To arrive at credible estimates of the elasticities of the production function, we trimmed our sample: we drop the observations when a firm reports that it has spent less than $5 \%$ or more than $100 \%$ of its revenue with intermediate consumption. Table 3.2 presents descriptive statistics of the estimated elasticities. We also present, in Table 3.3 the estimates of the TFP and the wedges as presented in equations $3-17,3-18$, and $3-19$, as well as a measure for the local returns to scale by summing the production function elasticities, i.e. $\phi_{j t}=\theta_{j t}^{L}+\theta_{j t}^{K}+\theta_{j t}^{M}$.

We note that the GNR methodology provides more reasonable estimates of the production function since firms exhibit constant returns to scale. As it turns out, our estimates of the production function are similar to those found in Chen et al. (2018). In their paper, they estimate capital, labor, and intermediate consumption elasticities of $0.22,0.447$, and 0.247 respectively. On the other hand, Gandhi et al. (2018) estimate their means to be, respectively, $0.14,0.34$, and 0.54 using Colombian data, and 0.16, 0.38, and 0.55 using Chilean data. 
Table 3.2: Descriptive statistics of elasticities estimated using the GNR framework in 1996

\begin{tabular}{|c|c|c|c|c|c|c|c|c|c|}
\hline & \multicolumn{3}{|c|}{$\theta^{L}$} & \multicolumn{3}{|c|}{$\theta^{K}$} & \multicolumn{3}{|c|}{$\theta^{M}$} \\
\hline & NYPSOE & CG & $\mathrm{P}$ & NYPSOE & CG & $\mathrm{P}$ & NYPSOE & CG & $\mathrm{P}$ \\
\hline Mean & 0.40 & 0.45 & 0.41 & 0.22 & 0.23 & 0.22 & 0.39 & 0.36 & 0.39 \\
\hline Standard Deviation & 0.11 & 0.12 & 0.11 & 0.05 & 0.05 & 0.05 & 0.14 & 0.13 & 0.14 \\
\hline $1^{s t}$ percentile & 0.10 & 0.15 & 0.12 & 0.09 & 0.08 & 0.08 & 0.13 & 0.09 & 0.11 \\
\hline $5^{t h}$ percentile & 0.20 & 0.26 & 0.22 & 0.14 & 0.16 & 0.13 & 0.19 & 0.15 & 0.18 \\
\hline $10^{t h}$ percentile & 0.26 & 0.29 & 0.26 & 0.16 & 0.17 & 0.16 & 0.22 & 0.18 & 0.22 \\
\hline $25^{t h}$ percentile & 0.32 & 0.36 & 0.33 & 0.19 & 0.19 & 0.19 & 0.30 & 0.26 & 0.30 \\
\hline $50^{t h}$ percentile & 0.39 & 0.44 & 0.40 & 0.22 & 0.22 & 0.22 & 0.38 & 0.35 & 0.38 \\
\hline $75^{t h}$ percentile & 0.47 & 0.53 & 0.48 & 0.25 & 0.26 & 0.25 & 0.48 & 0.45 & 0.47 \\
\hline $90^{t h}$ percentile & 0.54 & 0.62 & 0.56 & 0.28 & 0.28 & 0.28 & 0.57 & 0.53 & 0.57 \\
\hline $95^{t h}$ percentile & 0.60 & 0.66 & 0.62 & 0.29 & 0.30 & 0.30 & 0.65 & 0.56 & 0.64 \\
\hline $99^{t h}$ percentile & 0.69 & 0.76 & 0.70 & 0.33 & 0.43 & 0.36 & 0.82 & 0.78 & 0.79 \\
\hline Observations & 608 & 174 & 27167 & 608 & 174 & 27167 & 586 & 162 & 26257 \\
\hline
\end{tabular}

Table 3.3 also shows that the perceived prices of labor are higher in Brazil. In other words, firms tend to hire fewer workers than the optimal bundle. This problem does not seem to be worse across SOEs. Conversely, the perceived price of capital seems to be lower, especially among SOEs.

In the next chapter, we assess whether privatization enhances the TFP of firms, i.e., $\omega$, which is calculated by equation 3-17, and whether it eliminates some of the distortions in input choice, which is calculated by equations 3-18 and 3-19, enhancing what we call allocative efficiency. 
Table 3.3: Descriptive Statistics of variables obtained with the GNR estimates

\begin{tabular}{|c|c|c|c|c|c|c|}
\hline & NYPSOE & \multicolumn{2}{|l|}{$\phi$} & NYPSOE & $\begin{array}{l}\omega^{C G} \\
\end{array}$ & $\mathrm{P}$ \\
\hline Mean & 1.01 & 1.03 & 1.02 & 6.64 & 6.59 & 6.64 \\
\hline Standard Deviation & 0.04 & 0.07 & 0.05 & 0.24 & 0.29 & 0.24 \\
\hline $1^{\text {st }}$ percentile & 0.94 & 0.94 & 0.94 & 6.01 & 5.91 & 5.83 \\
\hline $5^{\text {th }}$ percentile & 0.96 & 0.96 & 0.96 & 6.23 & 6.09 & 6.18 \\
\hline $10^{t h}$ percentile & 0.97 & 0.97 & 0.97 & 6.33 & 6.27 & 6.32 \\
\hline $25^{\text {th }}$ percentile & 0.98 & 0.99 & 0.99 & 6.51 & 6.45 & 6.52 \\
\hline $50^{\text {th }}$ percentile & 1.00 & 1.01 & 1.01 & 6.69 & 6.65 & 6.68 \\
\hline $75^{\text {th }}$ percentile & 1.02 & 1.04 & 1.04 & 6.81 & 6.78 & 6.81 \\
\hline $90^{\text {th }}$ percentile & 1.06 & 1.12 & 1.09 & 6.88 & 6.87 & 6.90 \\
\hline $95^{\text {th }}$ percentile & 1.09 & 1.15 & 1.12 & 6.94 & 6.94 & 6.94 \\
\hline $99^{\text {th }}$ percentile & 1.16 & 1.17 & 1.20 & 7.03 & 7.05 & 7.03 \\
\hline Observations & 586 & 162 & 26257 & 586 & 162 & 2625 \\
\hline & \multicolumn{3}{|c|}{$\overline{\tau^{L}}$} & \multicolumn{3}{|c|}{$\tau^{K}$} \\
\hline Mean & 1.93 & 1.77 & 2.00 & 0.58 & 0.50 & 0.79 \\
\hline Standard Deviation & 1.44 & 1.59 & 4.35 & 4.28 & 1.18 & 8.14 \\
\hline $1^{\text {st }}$ percentile & 0.33 & 0.21 & 0.37 & 0.01 & 0.02 & 0.01 \\
\hline $5^{\text {th }}$ percentile & 0.57 & 0.48 & 0.60 & 0.03 & 0.03 & 0.03 \\
\hline $10^{\text {th }}$ percentile & 0.74 & 0.57 & 0.75 & 0.05 & 0.05 & 0.05 \\
\hline $25^{\text {th }}$ percentile & 1.07 & 0.96 & 1.10 & 0.10 & 0.12 & 0.09 \\
\hline $50^{\text {th }}$ percentile & 1.53 & 1.36 & 1.64 & 0.18 & 0.20 & 0.18 \\
\hline $75^{\text {th }}$ percentile & 2.30 & 2.06 & 2.47 & 0.38 & 0.37 & 0.39 \\
\hline $90^{\text {th }}$ percentile & 3.69 & 3.12 & 3.65 & 0.77 & 0.73 & 1.02 \\
\hline $95^{\text {th }}$ percentile & 4.62 & 3.72 & 4.60 & 1.32 & 1.34 & 2.08 \\
\hline $99^{\text {th }}$ percentile & 7.44 & 10.8 & 7.66 & 4.43 & 7.61 & 10.2 \\
\hline Observations & 586 & 162 & 26255 & 586 & 162 & 2625 \\
\hline
\end{tabular}




\section{4}

\section{Empirical Strategy and Results}

\section{1}

\section{Empirical Strategy}

Our empirical strategy in estimating the impacts of privatization is the following. We test the effect of privatization using SOEs as the control group for the estimates. Since the control group is reduced in numbers, we follow Borusyak and Jaravel $(2017)^{1}$. Our main specification is the following

$$
\begin{aligned}
\omega_{j t} & =\sum_{p=0}^{7} \delta_{p}^{\omega} * \text { privatization }_{j t}^{p}+\lambda_{s t}^{\omega}+\lambda_{j}^{\omega}+\epsilon_{j t}^{\omega} \\
\log \left(\tau_{j t}^{K}\right) & =\sum_{p=0}^{7} \delta_{p}^{K} * \text { privatization }_{j t}^{p}+\lambda_{s t}^{K}+\lambda_{j}^{K}+\epsilon_{j t}^{K} \\
\log \left(\tau_{j t}^{L}\right) & =\sum_{p=0}^{7} \delta_{p}^{L} * \text { privatization }_{j t}^{p}+\lambda_{s t}^{L}+\lambda_{j}^{L}+\epsilon_{j t}^{L}
\end{aligned}
$$

where $p$ is the number of years passed since the instance of privatization; privatization $_{j t}^{p}$ is a dummy that indicates if a firm was privatized $p$ years prior to year $t$, except for privatization $_{j t}^{7}$, which is a dummy that indicates whether the firm was privatized seven or more years earlier. Specifications 4-1, 4-2, and 4-3 assumes that there are parallel trends prior to privatization.

Table 2.1 shows us that the SOEs that did not participate in the PND are substantially different from the ones that were privatized. Thus, it is clear that our empirical strategy should include firm fixed effects to account for this firm-level heterogeneity.

We also control for sector-year fixed effects. Once we control for firmlevel fixed effects and sector-year fixed effects, our identification assumption is the following: the timing of the privatization of a given firm is exogenous to its productivity trends. One could argue that this may not be the case. For example, suppose an SOE finds an investment project that would boost its productivity, but, to have the resources for this investment, the government has to privatize this firm. In this case, privatization would be motivated by an

${ }^{1}$ Their paper shows that in event studies with no control group, the canonical difference in difference estimates does not recover a reasonable weighted average of the treatment effect 
expected increase in the firm's productivity, and we would be overestimating the effect of privatization. We argue, however, that this is highly unlikely. First, the PND was mainly motivated to deal with the fiscal crisis. Also, as figure 2.1 shows, the PND privatized a large number of firms in a short period. Thus, we find it unlikely that privatization was somehow coordinated to privatize the firms that were expected to become more productive in that year.

We chose to not include private firms in the regressions since we would lose one mechanism through which privatized firms increase their efficiency, which is how firms respond to their competitors. Say a competitor innovates and becomes more efficient. A privatized company may be more inclined to copy their competitor than an SOE. So, in this example, an innovation of the competitor will affect the sector-year fixed effect. If a privatized company is more likely than the SOE to internalize the innovation, then, our identification of parameter $\delta$ will come from how far the SOEs deviate from the sector-year fixed effect, and not how a privatized firm distances itself from the control group (not privatized SOEs) following privatization.

\section{2 \\ Privatization Effects}

\subsection{1}

\section{Testing Parallel Trends}

Following Borusyak and Jaravel (2017), we regress

$$
\begin{aligned}
\omega_{j t} & =\sum_{p=-5}^{7} \delta_{p}^{\omega} * \text { privatization }_{j t}^{p}+\lambda_{s t}^{\omega}+\lambda_{j}^{\omega}+\epsilon_{j t}^{\omega} \\
\log \left(\tau_{j t}^{K}\right) & =\sum_{p=-5}^{7} \delta_{p}^{K} * \text { privatization }_{j t}^{p}+\lambda_{s t}^{K}+\lambda_{j}^{K}+\epsilon_{j t}^{K} \\
\log \left(\tau_{j t}^{L}\right) & =\sum_{p=-5}^{7} \delta_{p}^{L} * \text { privatization }_{j t}^{p}+\lambda_{s t}^{L}+\lambda_{j}^{L}+\epsilon_{j t}^{L}
\end{aligned}
$$

As Borusyak and Jaravel (2017) show, equations 4-4, 4-5, and 4-6 are underidentified. Thus, we follow their suggestion ${ }^{2}$ and impose $\delta_{-1}^{\chi}=\delta_{-4}^{\chi}=0$ with $\chi$ being $\omega, K$, and $L$. They also claim that the estimates of the regression of this model should only be used to test parallel trends as it should not estimate these effects efficiently.

\footnotetext{
${ }^{2}$ In a setting with no control group (in our case, the control group is small when compared to the treatment group), we need to impose at least 2 restrictions to pin down a constant term and a linear term in the treatment and anticipation of treatment effects. We choose periods -1 and -4 to set the restriction, since Borusyak and Jaravel (2017) show that choosing periods far away from each other should reduce the standard errors of the estimators.
} 
Panel A: TFP $(\omega)$

with Year Fixed-Effects

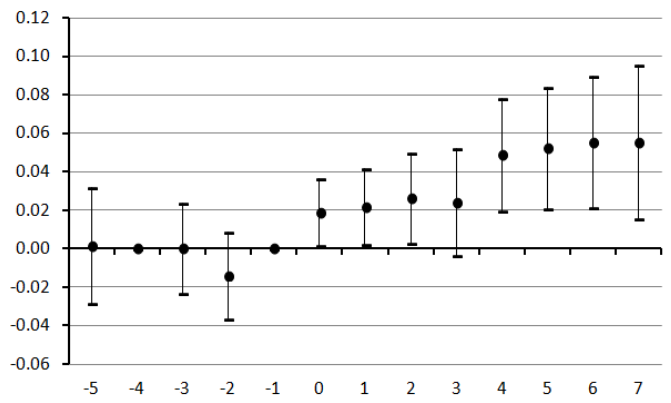

Panel B: wedge on Labor $\left(\ln \left(\tau^{L}\right)\right)$

with Year Fixed-Effects

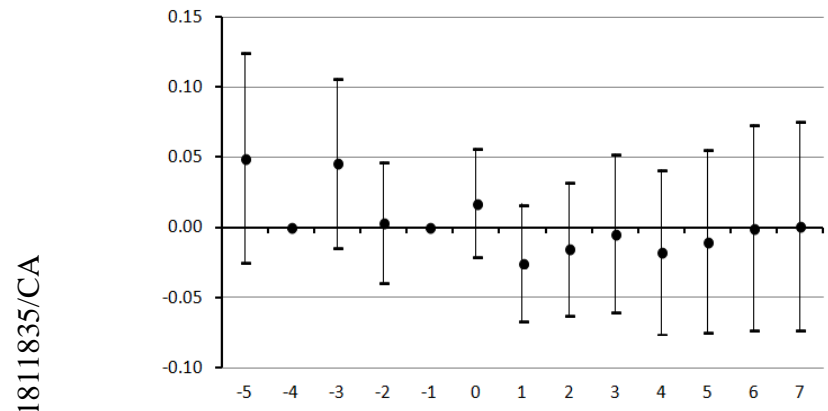

Panel C: wedge on Capital $\left(\ln \left(\tau^{K}\right)\right)$

with Year Fixed-Effects

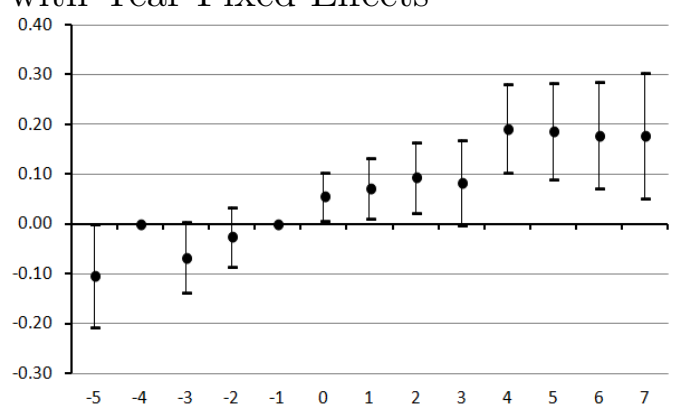

with Sector-Year Fixed-Effects

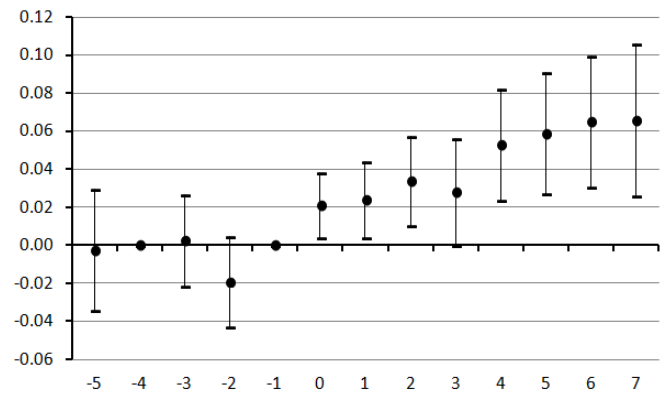

with Sector-Year Fixed-Effects

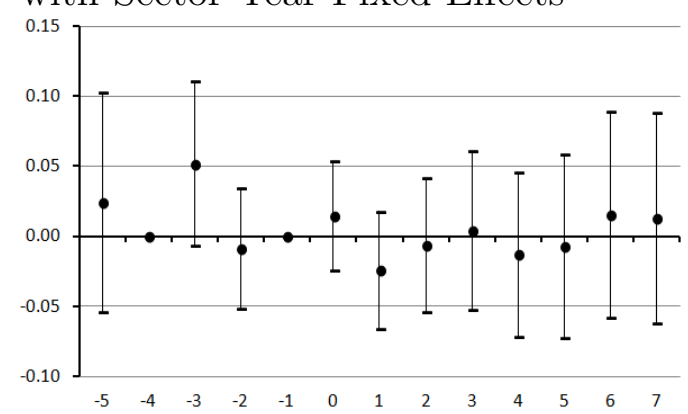

with Sector-Year Fixed-Effects

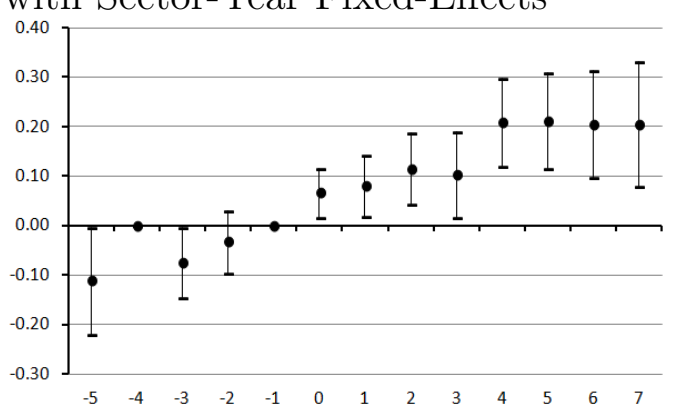

Figure 4.1: Parallel trend test of TFP and wedges of labor and capital. Panels $\mathrm{A}, \mathrm{B}$ and $\mathrm{C}$ present the $\delta$ coefficients displayed in equations 4-4, 4-6 and 4-5. Vertical bands display $90 \%$ confidence intevals constructed with robust standard errors. Panel A: number of Observations is 9245, and clusters, 1080; Panel B: number of Observations is 9187, and clusters, 1079; Panel C: number of Observations is 9234, and clusters, 1080.

The results in figure 4.1 do not point to different trends of productivity and the wedge on labor of the control group and of firms that participated in the PND. However, the coefficient for the effect on the wedge of capital 5 years 
or more before the event of privatization is negative and marginally significant at $10 \%$. This suggests that SOEs tend to hire more capital than the optimal amount than their counterpart long before being privatized and reduce their capital as the privatization event approaches. One possible explanation to this, is that firms that were privatized from 2001 onward were already selling assets in the 1990s.

\subsection{2}

\section{Estimated effects}

Figure 4.2 presents the regression of equations $4-1,4-2$, and $4-3$. The results point to an increase in the productivity of firms and an increase in the perceived price of capital.

One could ask is if this increment on $\tau^{K}$ can be interpreted as an enhancement in allocative efficiency. Table 3.3 shows, on average, firms perceive lower prices of capital. This is suggestive evidence that we can interpret this increase in perceived prices as an enhancement of allocative efficiency. To test this more rigorously, we also test two other specifications. In the first, we test if privatization has reduced the distance of the wedges to $1^{3}$. To do this, we simply regress specification 4-2 and 4-3 but change the dependent variable by the absolute values, i.e. $\left|\log \left(\tau^{K}\right)\right|$ and $\left|\log \left(\tau^{L}\right)\right|$, and regress:

$$
\begin{aligned}
\left|\log \left(\tau_{j t}^{K}\right)\right| & =\sum_{p=0}^{7} \delta_{p}^{|K|} * \text { privatization }_{j t}^{p}+\lambda_{s t}^{|K|}+\lambda_{j}^{|K|}+\epsilon_{j t}^{|K|} \\
\left|\log \left(\tau_{j t}^{L}\right)\right| & =\sum_{p=0}^{7} \delta_{p}^{|L|} * \text { privatization }_{j t}^{p}+\lambda_{s t}^{|L|}+\lambda_{j}^{|L|}+\epsilon_{j t}^{|L|}
\end{aligned}
$$

We use this measure of distance since the wedge is a scalar that multiplies the actual price to get the perceived price. Intuitively, speaking, suppose for example that the wedge is equal to 0.5 . This should mean that firms perceive prices as being half of their real value. If it is 2 , they perceive as being double the value. Taking the absolute value of the logarithm has the advantage that the regression equation interprets these distortions with the same weight. Moreover, since the minimum value, zero, can only happen when there is no distortion, $\tau=1$, a negative coefficient can only mean an enhancement in allocative efficiency.

As it turns out, the results corroborate the claim that privatization was accompanied by an enhancement in allocative efficiency of capital. Neverthe-

${ }^{3}$ Petrin and Sivadasan (2013) also test the reduction in distortions in allocation. Since they have access to price data, they do this by estimating the effects on the absolute value of the difference between prices and their estimate of marginal productivity 
Panel A: TFP $(\omega)$

with Year Fixed-Effects

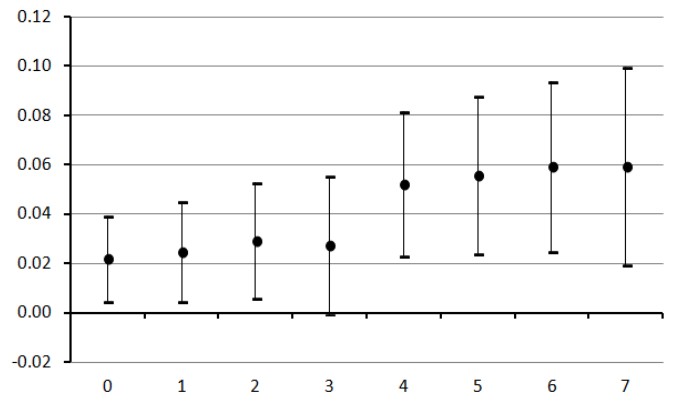

Panel B: wedge on Labor $\left(\ln \left(\tau^{L}\right)\right)$

with Year Fixed-Effects

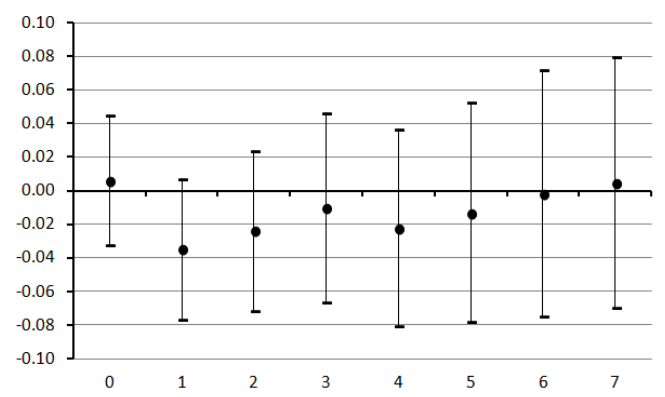

Panel C: wedge on Capital $\left(\ln \left(\tau^{K}\right)\right)$

with Year Fixed-Effects

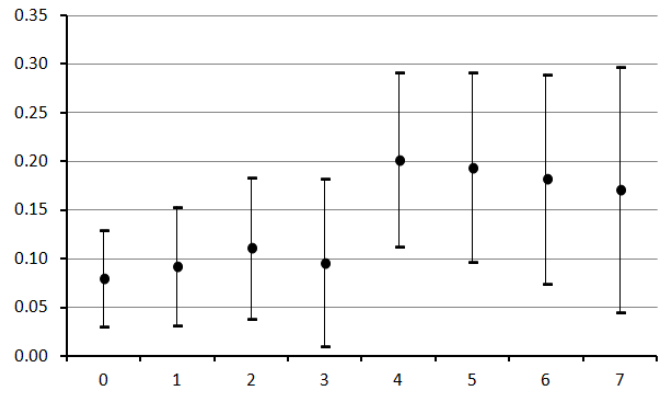

with Sector-Year Fixed-Effects

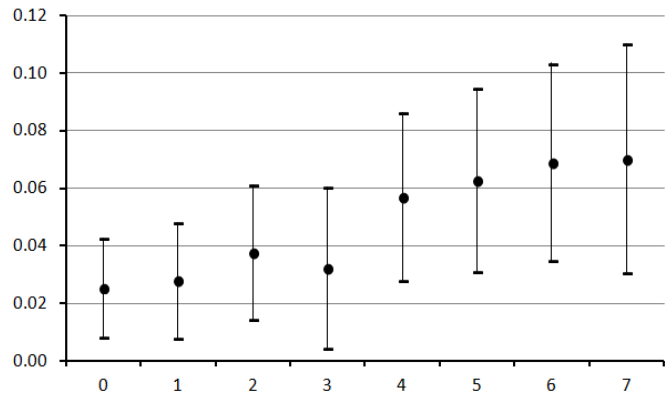

with Sector-Year Fixed-Effects

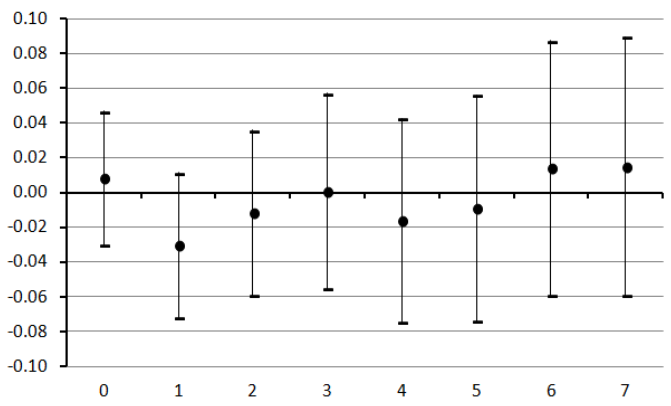

with Sector-Year Fixed-Effects

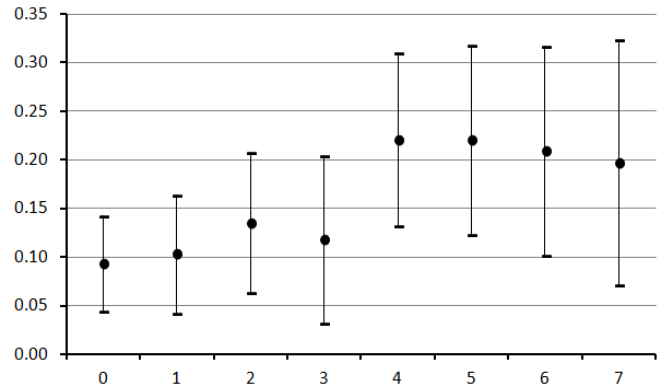

Figure 4.2: Effects of Privatization onTFP and wedges of labor and capital. Panels A, B and C present the $\delta$ coefficients displayed in equations 4-1, 4-3 and 4-2. Vertical bands display $90 \%$ confidence intervals constructed with robust standard errors. Panel A: number of Observations is 9245, and clusters, 1080; Panel B: number of Observations is 9187, and clusters, 1079; Panel C: number of Observations is 9234, and clusters, 1080.

less, the claim that privatization caused this improvement is still questionable since these firms were already selling their assets before privatization.

Surprisingly, this specification, with year fixed-effects, suggests that after 
Panel A: wedge on Labor $\left(\left|\ln \left(\tau^{L}\right)\right|\right)$

with Year Fixed-Effects

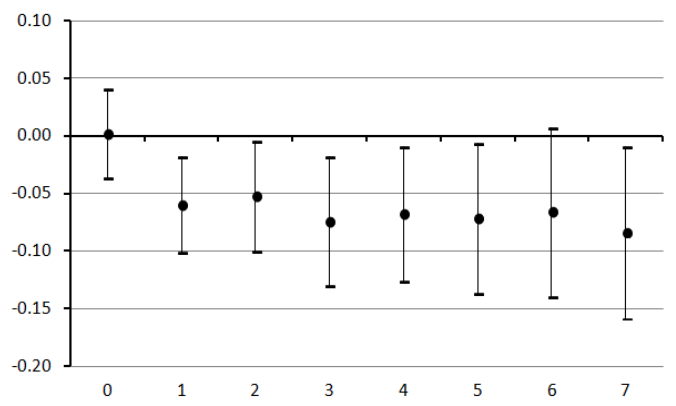

Panel B: wedge on Capital $\left(\left|\ln \left(\tau^{K}\right)\right|\right)$

with Year Fixed-Effects

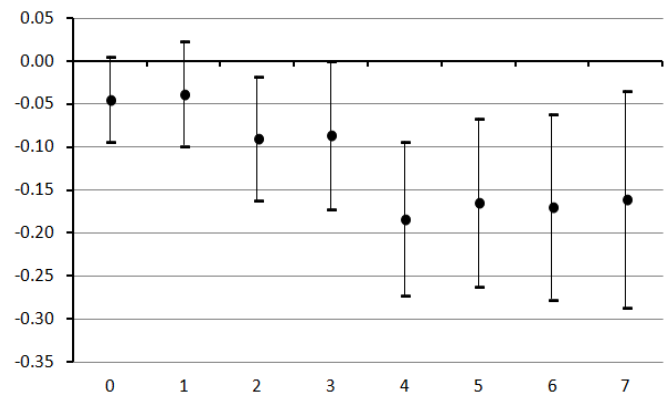

with Sector-Year Fixed-Effects

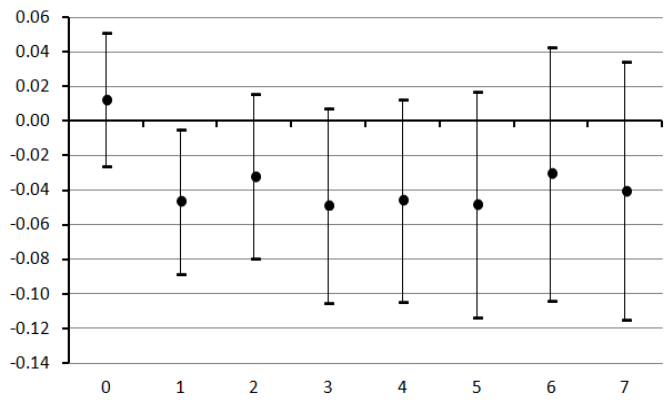

with Sector-Year Fixed-Effects

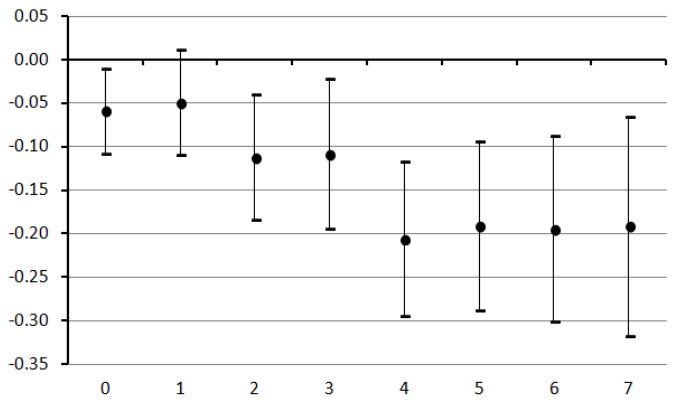

Figure 4.3: Effect of Privatization on allocative efficiency. Panels A and B present the $\delta$ coefficients displayed in equations 4-8 and 4-7. Vertical bands display $90 \%$ confidence intervals constructed with robust standard errors. Panel A: number of Observations is 9187, and clusters, 1079; Panel B: number of Observations is 9234, and clusters, 1080.

privatization, SOEs have improved their allocative efficiency concerning labor as well. The significance, however, is not robust to sector-year fixed-effects. Nevertheless, the fact that the coefficients are consistently negative suggests that Panel B in figure 4.2 is not capturing a heterogeneous pattern with regards to the allocation of labor. In other words, it may be the case that firms that were employing more labor than the optimal amount, hired less workers, and firms hiring less, hired more after privatization.

We test this heterogeneity with the following specification. Let $\tilde{t}_{j}$ denote the year before the event of privatization, i.e., if firm $j$ was privatized in year 
$t$, than $\tilde{t}_{j}=t-1$.

$$
\begin{aligned}
& \log \left(\tau_{j t}^{K}\right)=\left(\sum_{p=0}^{7} \delta_{p}^{K+} \text { privatization }_{j t}^{p}\right) * I_{K}^{+} \\
&\left(\sum_{p=0}^{7} \delta_{p}^{K-} \text { privatization }_{j t}^{p}\right) * I_{K}^{-} \\
&+\lambda_{s t}^{K}+\lambda_{j}^{K}+\epsilon_{j t}^{K} \\
& \log \left(\tau_{j t}^{L}\right)=\left(\sum_{p=0}^{7} \delta_{p}^{L+} \text { privatization }_{j t}^{p}\right) * I_{L}^{+} \\
&\left(\sum_{p=0}^{7} \delta_{p}^{L-} \text { privatization }_{j t}^{p}\right) * I_{L}^{-} \\
&+\lambda_{s t}^{L}+\lambda_{j}^{L}+\epsilon_{j t}^{L}
\end{aligned}
$$

where $I_{K}^{+}\left(I_{K}^{-}\right)$is an indicator function that is equal to 1 if the wedge $\tau_{j t}^{K}$ is greater (less) than 1 in $\tilde{t}_{j}$. Symmetrically $I_{L}^{+}\left(I_{L}^{-}\right)$indicates whether $\tau^{L}$ is greater (less) than 1 in $\tilde{t}_{j}$. In this specification, firms should improve their allocative efficiency following privatization if $\delta_{p}^{+K}<0, \delta_{p}^{+L}<0, \delta_{p}^{-K}>0$ and $\delta_{p}^{-L}>0$.

Table 4.1 presents the results. As it turns out, almost all coefficients are statistically significant and point to the direction of improvement of allocative efficiency for both capital and labor.

We also note that the estimates of $\delta_{p}^{-K}$ are very similar to those presented in figure 4.2. This is expected since more than $90 \%$ of the sample have a wedge of capital lower than 1 in 1996.

It is noteworthy that the estimates of $\delta_{p}^{-L}$ and $\delta_{p}^{+L}$ are much larger than the coefficients presented in figures 4.2 and 4.3. This suggests that firms that were employing less the the optimal amount of labor, hired more workers after privatization. Conversely, firms that employed more workers, hired less workers following privatization. These patterns counteracted one another, which lead to an estimate of specification 4-3 close to zero. The fact that the estimates of the coefficients of equation 4-8 are negative with questionable significance suggests that when firms hired more (or less) labor to correct their allocation, they may have overshot in their correction.

We now discuss the interpretations of these results. 
Table 4.1: Estimates of equations 4-9 and 4-10

\begin{tabular}{|c|c|c|c|c|}
\hline & (1) & (2) & (3) & (4) \\
\hline Exp of dep. Variable & $\tau^{K}$ & $\tau^{K}$ & $\tau^{L}$ & \\
\hline \multirow[t]{2}{*}{$\delta_{0}^{+}$} & -0.145 & -0.138 & -0.0373 & -0.0335 \\
\hline & $(0.0933)$ & $(0.0962)$ & $(0.0250)$ & $(0.0256)$ \\
\hline \multirow[t]{2}{*}{$\delta_{1}^{+}$} & $-0.207^{*}$ & -0.191 & $-0.0918^{* * *}$ & $-0.0890 * * *$ \\
\hline & $(0.119)$ & $(0.121)$ & $(0.0269)$ & $(0.0277)$ \\
\hline \multirow[t]{2}{*}{$\delta_{2}^{+}$} & $-0.233^{*}$ & -0.202 & $-0.0849^{* * *}$ & $-0.0747^{* *}$ \\
\hline & $(0.125)$ & $(0.126)$ & $(0.0307)$ & $(0.0318)$ \\
\hline \multirow[t]{2}{*}{$\delta_{3}^{+}$} & $-0.461^{* * *}$ & $-0.413^{* *}$ & $-0.104^{* * *}$ & $-0.0903^{* *}$ \\
\hline & $(0.174)$ & $(0.173)$ & $(0.0345)$ & $(0.0361)$ \\
\hline \multirow[t]{2}{*}{$\delta_{4}^{+}$} & $-0.291^{* *}$ & $-0.261^{*}$ & $-0.110^{* * *}$ & $-0.104^{* * *}$ \\
\hline & $(0.137)$ & $(0.141)$ & $(0.0356)$ & $(0.0383)$ \\
\hline \multirow[t]{2}{*}{$\delta_{5}^{+}$} & -0.161 & -0.128 & $-0.106^{* * *}$ & $-0.0975^{* *}$ \\
\hline & $(0.159)$ & $(0.161)$ & $(0.0390)$ & $(0.0408)$ \\
\hline \multirow[t]{2}{*}{$\delta_{6}^{+}$} & $-0.453^{* *}$ & $-0.391^{*}$ & $-0.101^{* *}$ & $-0.0818^{*}$ \\
\hline & $(0.220)$ & $(0.228)$ & $(0.0428)$ & $(0.0434)$ \\
\hline \multirow[t]{2}{*}{$\delta_{7}^{+}$} & $-0.696 * * *$ & $-0.630 * * *$ & $-0.122^{* * *}$ & $-0.110 * *$ \\
\hline & $(0.174)$ & $(0.176)$ & $(0.0438)$ & $(0.0463)$ \\
\hline \multirow[t]{2}{*}{$\delta_{0}^{-}$} & $0.127^{* * *}$ & $0.138^{* * *}$ & $0.171^{* * *}$ & $0.177^{* * *}$ \\
\hline & $(0.0313)$ & $(0.0313)$ & $(0.0460)$ & $(0.0471)$ \\
\hline \multirow[t]{2}{*}{$\delta_{1}^{-}$} & $0.153^{* * *}$ & $0.162^{* * *}$ & $0.221^{* * *}$ & $0.234^{* * *}$ \\
\hline & $(0.0375)$ & $(0.0377)$ & $(0.0416)$ & $(0.0451)$ \\
\hline \multirow[t]{2}{*}{$\delta_{2}^{-}$} & $0.184^{* * *}$ & $0.206^{* * *}$ & $0.211^{* * *}$ & $0.225^{* * *}$ \\
\hline & $(0.0436)$ & $(0.0435)$ & $(0.0485)$ & $(0.0537)$ \\
\hline \multirow[t]{2}{*}{$\delta_{3}^{-}$} & $0.186^{* * *}$ & $0.204^{* * *}$ & $0.352^{* * *}$ & $0.353^{* * *}$ \\
\hline & $(0.0499)$ & $(0.0497)$ & $(0.0589)$ & $(0.0621)$ \\
\hline \multirow[t]{2}{*}{$\delta_{4}^{-}$} & $0.290^{* * *}$ & $0.300^{* * *}$ & $0.321^{* * *}$ & $0.325^{* * *}$ \\
\hline & $(0.0529)$ & $(0.0527)$ & $(0.0526)$ & $(0.0554)$ \\
\hline \multirow[t]{2}{*}{$\delta_{5}^{-}$} & $0.277^{* * *}$ & $0.297 * * *$ & $0.351^{* * *}$ & $0.326^{* * *}$ \\
\hline & $(0.0573)$ & $(0.0579)$ & $(0.0558)$ & $(0.0565)$ \\
\hline \multirow[t]{2}{*}{$\delta_{6}^{-}$} & $0.284^{* * *}$ & $0.304^{* * *}$ & $0.375^{* * *}$ & $0.364^{* * *}$ \\
\hline & $(0.0616)$ & $(0.0610)$ & $(0.0722)$ & $(0.0759)$ \\
\hline \multirow[t]{2}{*}{$\delta_{7}^{-}$} & $0.284^{* * *}$ & $0.307^{* * *}$ & $0.464^{* * *}$ & $0.441^{* * *}$ \\
\hline & $(0.0704)$ & $(0.0663)$ & $(0.0563)$ & $(0.0576)$ \\
\hline Observations & 9,234 & 9,234 & 9,187 & 9,187 \\
\hline R-squared & 0.105 & 0.184 & 0.193 & 0.271 \\
\hline Number of id & 1,080 & 1,080 & 1,079 & 1,079 \\
\hline Year FE & Yes & No & Yes & No \\
\hline Sector-Year FE & No & Yes & No & Yes \\
\hline
\end{tabular}

Robust standard errors in parentheses. Statistical significance at 10\%, 5\% and $1 \%$ is indicated by $* * *$ and ${ }^{* * *}$ respectively

\section{3}

\section{Discussion}

A natural line of questioning regarding our methodology is the following. TFP is a residual that captures various factors that affect the total output of 
the firm. Thus, one might question whether the TFP measure would already be capturing allocative inefficiencies. This indeed may happen under certain interpretations.

For the sake of simplicity, assume the production function is a CobbDouglas with known parameters (i.e. $f\left(k_{j t}, l_{j t}, m_{j t}\right)=\beta_{k} k_{j t}+\beta_{l} l_{j t}+\beta_{m} m_{j t}$ ), output and inputs levels are observed, but wedges and firm specific TFP are not know.

Consider the following interpretation.

Interpretation 1: All capital and labor hired are employed by the firm as inputs.

Suppose there is no idle capital or idle labor. The firm specific TFP would be recovered by equation $4-11$

$$
\omega_{j t}=y_{j t}-\left(\beta_{k} k_{j t}+\beta_{l} l_{j t}+\beta_{m} m_{j t}\right)
$$

regardless of whether the mix of inputs $\left(k_{j t}, l_{j t}, m_{j t}\right)$ is the cost minimizing bundle. The wedges, on the other hand, would be recovered by equations 4-12

$$
\begin{aligned}
\tau_{j t}^{K} & =\frac{\beta_{k}}{\beta_{m}} \frac{P_{t}^{M} M_{j t}}{r_{t} K_{j t}} \\
\tau_{j t}^{L} & =\frac{\beta_{l}}{\beta_{m}} \frac{P_{t}^{M} M_{j t}}{w_{t} L_{j t}}
\end{aligned}
$$

The main issue would arise if idle inputs are one of the factors explaining TFP. To see this, consider the following:

Interpretation 2: Let $k_{j t}$ and $l_{j t}$ denote the $\log$ of capital and labor hired by firm $j$ at time $t$. Let $k_{j t}^{*}$ and $l_{j t}^{*}$ denote the log of capital and labor that is actually used in production and is not observed by the econometrician. There exists some idle capital $k_{j t}^{i}>0$ and idle labor $l_{j t}^{i}>0$ such that $k_{j t}-k_{j t}^{*}=k_{j t}^{i}$ and $l_{j t}-l_{j t}^{*}=l_{j t}^{i}$.

This sort of friction assumed in interpretation 2 should be captured in both of the efficiency measures identified by the econometrician. Consider the case of idle capital.

On one hand, idle capital affects the allocative efficiency measure. It should reduce perceived prices on capital by increasing the denominator in equation 4-12.

On the other hand, it should reduce TFP as well. To see this, let $\omega^{*}$ be the TFP not accounting for idle capital, i.e. $\omega_{j t}^{*}=y_{j t}-\left(\beta_{k} k_{j t}^{*}+\beta_{l} l_{j t}+\beta_{m} m_{j t}\right)$. Since we do not observe idle capital, we would compute the TFP as in equation 4-11. Thus, the fact that the firm does not use all of its capital hired would reduce TFP by $\omega_{j t}^{*}-\omega_{j t}=\beta_{k}\left(k_{j t}-k_{j t}^{*}\right)=\beta_{k} k_{j t}^{i}$. 
The correction of idle capital, then, would appear as both an improvement in the productive efficiency, i.e. as an increase in TFP, and as an improvement of allocative efficiency, i.e. as an increase in perceived prices of capital. Thus, the interpretation we gave thus far that these measures capture different mechanisms of an improvement in efficiency might be questionable. While we feel there is some validity to this criticism, our preferred interpretation is that these measures still capture different mechanisms of efficiency improvement.

The more practical reasons are the following. First, interpretation 2 requires that idle capital be positive. Thus, the correction in idle capital can only entail an increase in a simultaneous increase of TFP and an increase in the wedge of capital. As we have seen in table 4.1, firms also correct their wedge downward, which suggests that idle capital and labor are not the sole reason why firms are correcting their perception of prices. The second reason is that as we have seen in figure 4.1, there is evidence that before privatization firms were already increasing their perception of capital but their TFP was not affected before privatization.

But, ultimately, the decision whether to interpret our results based on interpretation 1 or interpretation 2 depends more on what the researcher believes that the production function should capture. Should the production function be interpreted as a quantitative relation between hired inputs and observed output (interpretation 1) or as a quantitative relation between the inputs that are actually put in the production line and the output produced (interpretation 2)? We feel the former view is more fertile to research since researchers rarely would be able to quantify this "amount of input that is actually used in production". Under assumption 1, when firms reduce the amount of idle capital (or labor), this should be interpreted as a policy that improves the efficiency of firms by two separate mechanisms: it increases the productive efficiency, since firms are extracting more output of their inputs, and it also increases allocative efficiency since firms do not need to hire unproductive inputs when increasing their product.

\section{4}

\section{Economic Significance}

The sections above have assessed the impact of privatization on the TFP and wedges in FOC of the cost minimization problem. Our motivation for studying these effects is to evaluate whether privatization leads to a reduction in the costs of production by firms. In this section, we seek to understand the economic significance of the estimated impacts. Thus, we now turn to some calculations to measure the reduction in the costs of production that the 
estimated effects entail.

Recall that firms should minimize costs, i.e, they should minimize the cost function $\mathcal{C}=w_{j t} L_{j t}+r_{j t} K_{j t}+P_{j t}^{M} M_{j t}$ subject to the level of production constraint. We assumed that distortions may lead firms to effectively solve problem 4-13, which we call the distorted cost minimization problem. Employing the notations introduced in problem 3-2, the distorted cost problem is written as

$$
\begin{array}{r}
\operatorname{Min}_{K_{j t}, L_{j t}, M_{j t}} \tau_{j t}^{L} w_{j t} L_{j t}+\tau_{j t}^{K} r_{j t} K_{j t}+P_{j t}^{M} M_{j t} \\
\text { s.t. } f\left(k_{j t}, l_{j t}, m_{j t}\right) \geq y_{j t}-\varepsilon_{j t}-\omega_{j t}
\end{array}
$$

This allowed us to estimate the TFP, $\omega_{j t}$, as well as the wedges $\tau_{j t}^{L}, \tau_{j t}^{K}$, based on the observed mix of inputs used by firm $j$ in period $t$. These variables impact the cost of production in the following way. The TFP reduces costs by slackening the restriction of the problem. The wedges on prices, on the other hand, affect costs by changing the mix of inputs used in production. Note that since the cost of production, which is given by the objective $\mathcal{C}$, by definition, the cost of production is minimal when $\tau_{j t}^{L}=\tau_{j t}^{K}=1$.

As discussed above, privatization leads to an increase in the TFP and brings $\tau_{j t}^{L}$ and $\tau_{j t}^{K}$ closer to 1 , which we interpret as an improvement in allocative efficiency. However, it is not clear by how much the costs fall due to these effects ${ }^{4}$. To estimate these effects we carry out the following exercise.

We restrict the following calculations only to the observations of firms during year $\tilde{t}_{j}$. We do this since the estimated effects should be interpreted as changes in TFP and wedges following privatization. Our analysis will be based on the solution of multiple specifications of the distorted cost minimization problem. Since the estimated production function has certain regions where the elasticities of capital and labor on the product are negative, some firms in some counterfactual specifications solve problem (4-13) by setting capital and labor to zero and rely only on intermediate consumption. We exclude these firms from the analysis as well. This leaves us with 535 privatized SOEs.

We, first, solve problem (4-13) for each firm, based on our estimates of $\omega_{j \tilde{t}_{j}}, \tau_{j \tilde{t}_{j}}^{L}$ and $\tau_{j \tilde{t}_{j}}^{K}$, and calculate the cost of production. As expected, the calculated cost of production is very similar to the observed production cost.

To assess the economic significance of the effects on TFP, we carry out exercise 1: we calculate the cost given the increase in $\omega$, in other words, we solve for each firm and for each $p$ period after the firm has been privatized

$$
\begin{array}{r}
\operatorname{Min}_{K_{j \tilde{t}_{j}}, L_{j \tilde{t}_{j}}, M_{j \tilde{t}_{j}}} \tau_{j \tilde{t}_{j}}^{L} w_{j \tilde{t}_{j}} L_{j \tilde{t}_{j}}+\tau_{j \tilde{t}_{j}}^{K} r_{j \tilde{t}_{j}} K_{j \tilde{t}_{j}}+P_{j \tilde{t}_{j}}^{M} M_{j \tilde{t}_{j}} \\
\text { s.t. } f\left(k_{j \tilde{t}_{j}}, l_{j \tilde{t}_{j}}, m_{j \tilde{t}_{j}}\right) \geq y_{j \tilde{t}_{j}}-\varepsilon_{j \tilde{t}_{j}}-\omega_{j \tilde{t}_{j}}-\hat{\delta}_{p}^{T F P}
\end{array}
$$

${ }^{4}$ Since the production function estimated is not homogeneous, even the estimated effect on TFP is not straightforwardly translated in an estimated effect on costs of production 
where $\hat{\delta}_{p}^{T F P}$ is the estimated effect of privatization on TFP presented in figure 4.2 panel A with year fixed-effects.

To assess the economic significance of the reduction in distortions in resource allocation, we carry out 2 exercises. In exercise 2, we first calculate wedges. For each period $p$ after privatization and each input, we calculate a wedge on capital given by

$$
\tilde{\tau}_{j p}^{k}= \begin{cases}\exp \left(\log \left(\tau_{j \tilde{t}_{j}}^{K}\right)-\hat{\delta}_{p}^{|K|}\right) & \text { if } \tau^{K} \leq 1 \\ \exp \left(\log \left(\tau_{j \tilde{t}_{j}}^{K}\right)+\hat{\delta}_{p}^{|K|}\right) & \text { otherwise }\end{cases}
$$

And then solve

$$
\begin{array}{r}
\operatorname{Min}_{K_{j \tilde{t}_{j}}, L_{j \tilde{j}_{j}}, M_{j \tilde{t}_{j}}} \tau_{j \tilde{t}_{j}}^{L} w_{j \tilde{t}_{j}} L_{j \tilde{t}_{j}}+\tilde{\tau}_{j p}^{K} r_{j \tilde{t}_{j}} K_{j \tilde{t}_{j}}+P_{j \tilde{t}_{j}}^{M} M_{j \tilde{t}_{j}} \\
\text { s.t. } f\left(k_{j \tilde{t}_{j}}, l_{j \tilde{j}_{j}}, m_{j \tilde{t}_{j}}\right)+\omega_{j \tilde{t}_{j}} \geq y_{j \tilde{t}_{j}}-\varepsilon_{j \tilde{t}_{j}}-\hat{\delta}_{p}^{T F P}
\end{array}
$$

where $\left.\hat{\delta}^{\mid} K\right|_{p}$ are the estimated coefficients presented in 4.3 panel A and B with year-fixed effects. In exercise 3 , we do the same to calculate new wedges in labor.

With these exercises, we obtain data in a panel structure where for each firm $j$ we have the observed cost 1 year prior to privatization $\left(\mathcal{C}_{j ;-1}\right)$, and for each period $p$, and each exercise $i \in\{1,2,3\}$ an estimate of the cost had this firm been privatized $p$ periods sooner $\left(\mathcal{C}_{j ; p}^{i}\right)$. We then plot the average costs of SOEs for each period $p$, i.e.,

$$
\overline{\mathcal{C}}_{p}=\frac{\sum_{j} \mathcal{C}_{j ; p}}{n}
$$

And the average percentage reduction for each firm in period $P$,

$$
\overline{\overline{\mathcal{C}}}_{p}=\frac{\sum_{j} \frac{\mathcal{C}_{j ;-1}-\mathcal{C}_{j ; p}}{\mathcal{C}_{j ;-1}}}{n}
$$

The average production costs of the firms are reported in figure (4.4). As expected, the main mechanism that drives costs down is the increase in TFP. However, the improvement in allocative efficiency is still economically significant: in the long run, $14.37 \%$ of the reduction in costs due to privatization is explained by an improvement in allocative efficiency. Moreover, If we look at the mean percentage decrease in costs, we see that on average, the correction in wedges explain 4.57 percentage points of the $36.50 \%$ decrease of costs in the long run. This states that the improvement in allocative efficiency has accounted for $12.49 \%$ of the total decrease in costs. 
Average Costs(in millions 2016 Reais)
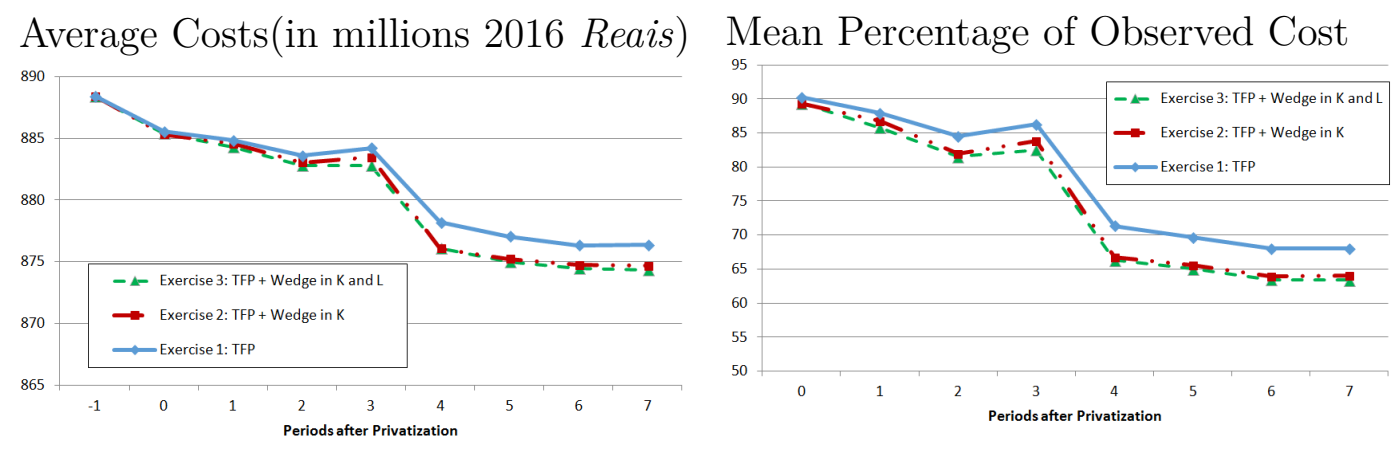

Figure 4.4: Evolution of Cost

Nevertheless, the average cost of SOEs does not change by much: in the long run, the cost reduces by $1.5 \%$. However, the effects of privatization on each firm on average seem to be much higher. On average, the firm reduces $36.59 \%$ of their costs in the long run. Chen et al. (2018) find that large Chinese SOEs have been less affected by privatization than small SOEs. Our calculations points to a similar finding. Since exploring this heterogeneity was not the point of this study, we present some preliminary investigations of this in the annex. The results corroborate the claim that larger firms were less affected.

While we would advise caution in reading the estimated cost decrease, the main takeaway here is that the allocative efficiency does account for an economically significant portion of the cost reduction followed by privatization.

We now turn to robustness checks.

\section{5}

\section{Robustness Checks}

Lastly, we conduct 3 robustness checks. In the first, we regress equations 4-1, 4-2, 4-3, 4-7 dropping the control group. We do this to avoid possible issues stemming from the fact that we stop observing many firms in the control group. This could potentially affect the year and sector-year fixed effects if, for example, we stop observing the less productive firms. The results are robust to this specification.

In the second, we balance our sample. We note that the effects on TFP seem robust to balancing the sample. However, the effect on the wedges disappear.

It is important to note that we have drastically reduced the number of observations in the sample. By balancing the sample, there remains only 140 firms. Thus, we carry out a third robustness check where we include only the 
Panel A: TFP $(\omega)$
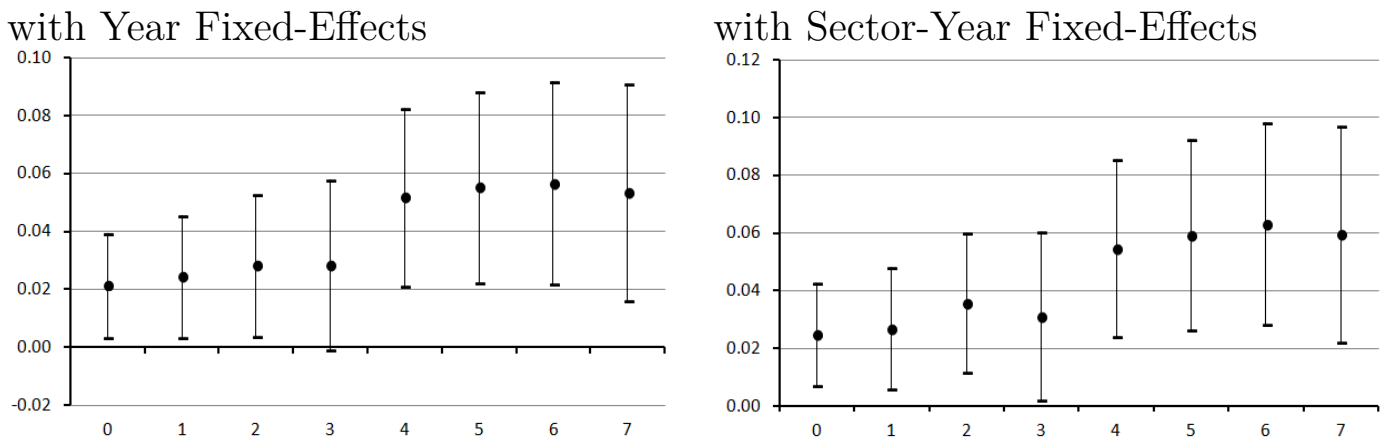

Panel B: wedge on Labor $\left(\ln \left(\tau^{L}\right)\right)$

with Year Fixed-Effects

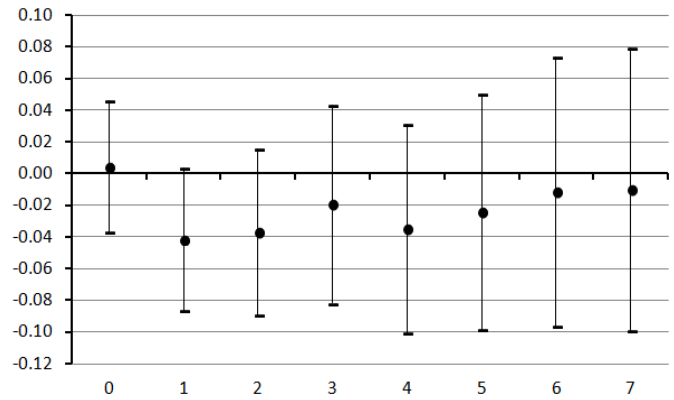

Panel C: wedge on Capital $\left(\ln \left(\tau^{K}\right)\right)$

with Year Fixed-Effects

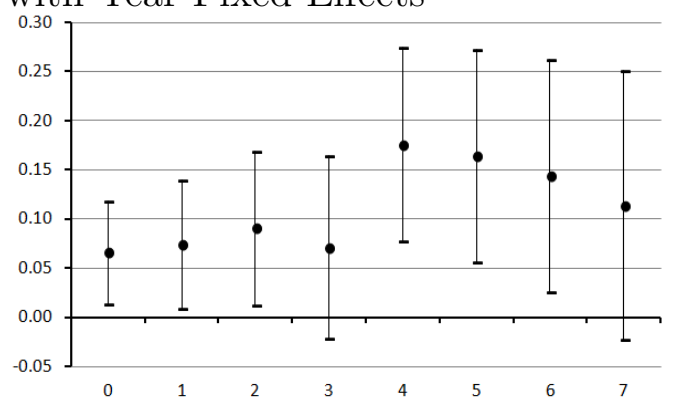

with Sector-Year Fixed-Effects

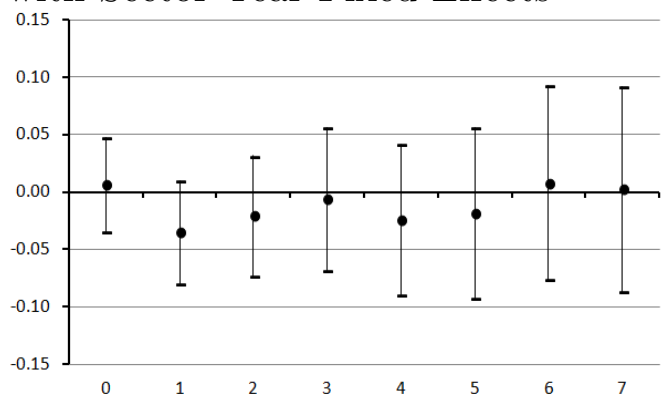

with Sector-Year Fixed-Effects

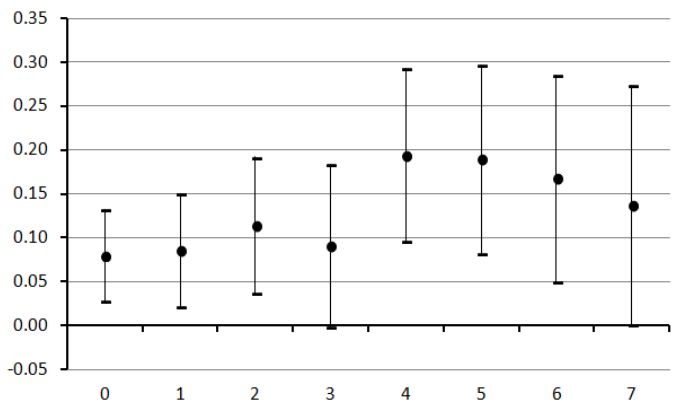

Figure 4.5: Effects of Privatization on TFP and wedges of labor and capital. No control group. Panels $\mathrm{A}, \mathrm{B}$ and $\mathrm{C}$ present the $\delta$ coefficients displayed in equations 4-1, 4-3 and 4-2. Vertical bands display 90\% confidence intervals constructed with robust standard errors. Panel A: number of Observations is 8509, and clusters, 815; Panel B: number of Observations is 8452, and clusters, 814; Panel C: number of Observations is 8500, and clusters, 815.

firms that were observed for 10 years or more during our sample period. The results are robust to this specification. 
Panel A: wedge on Labor $\left(\left|\ln \left(\tau^{L}\right)\right|\right)$

with Year Fixed-Effects

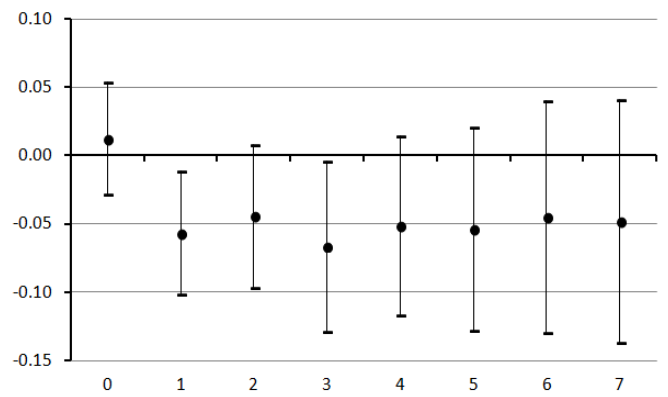

Panel B: wedge on Capital $\left(\left|\ln \left(\tau^{K}\right)\right|\right)$

with Year Fixed-Effects

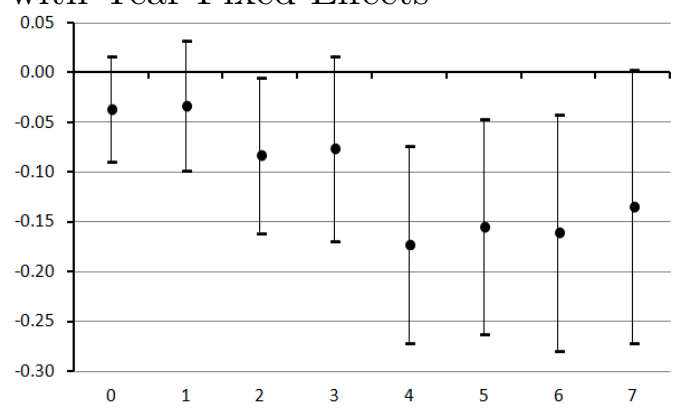

with Sector-Year Fixed-Effects

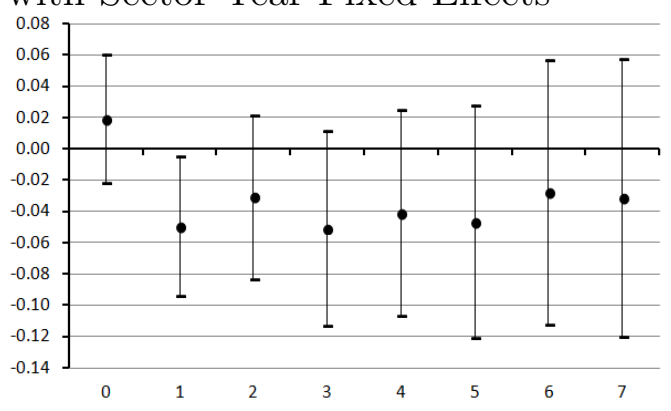

with Sector-Year Fixed-Effects

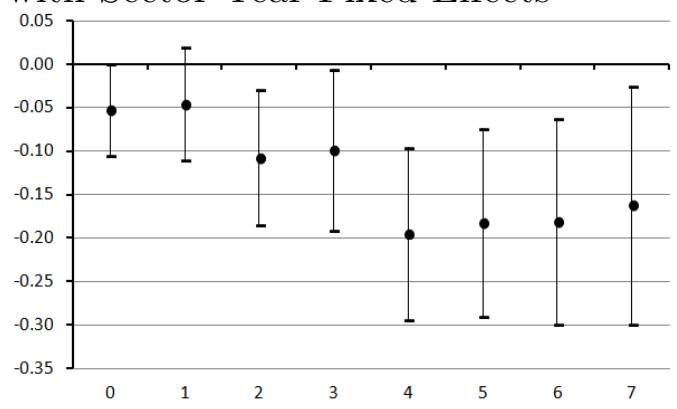

Figure 4.6: Effects of Privatization on TFP and wedges of labor and capital. No control group. Panels A abd B present the $\delta$ coefficients displayed in equations 4-8 and 4-7. Vertical bands display $90 \%$ confidence intervals constructed with robust standard errors. Panel A: number of Observations is 8452, and clusters, 814; Panel B: number of Observations is 8500 , and clusters, 815. 
Panel A: TFP $(\omega)$
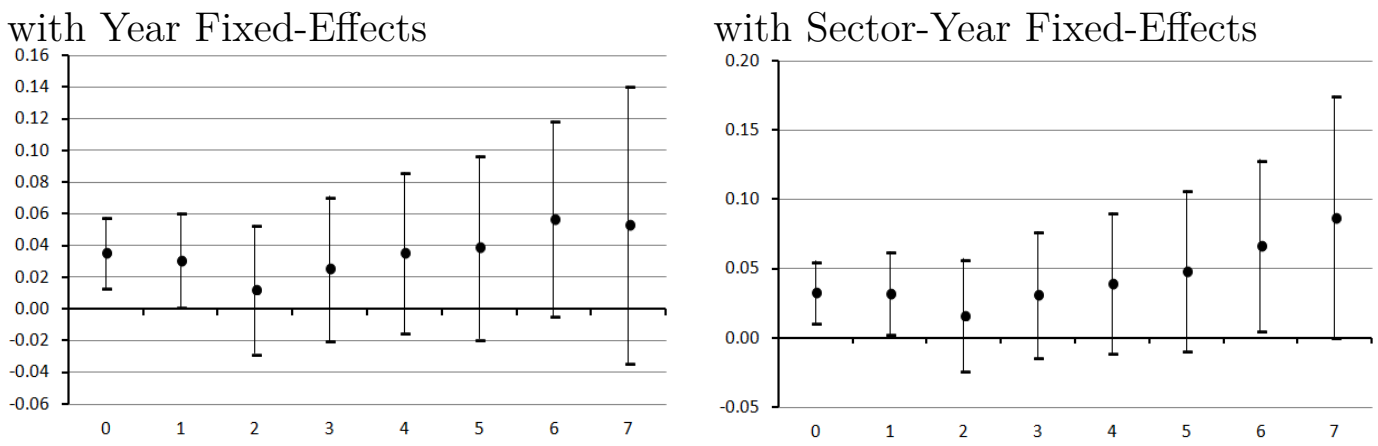

Panel B: wedge on Labor $\left(\ln \left(\tau^{L}\right)\right)$

with Year Fixed-Effects

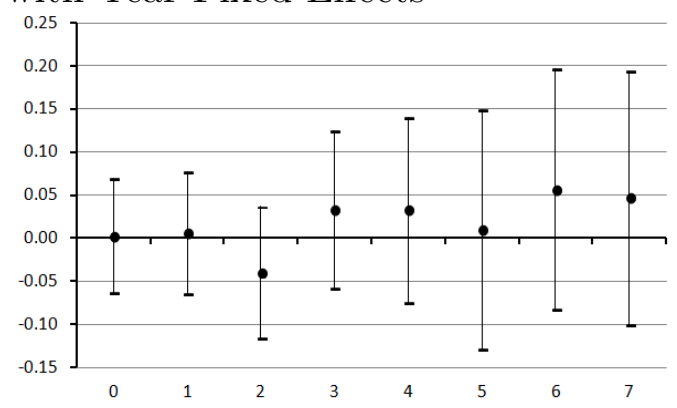

Panel C: wedge on Capital $\left(\ln \left(\tau^{K}\right)\right)$

with Year Fixed-Effects

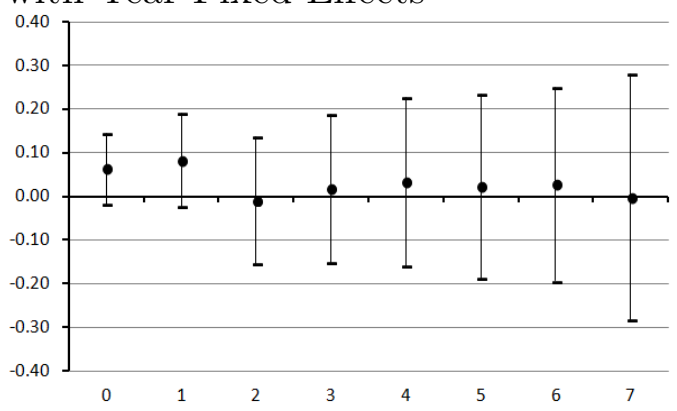

with Sector-Year Fixed-Effects

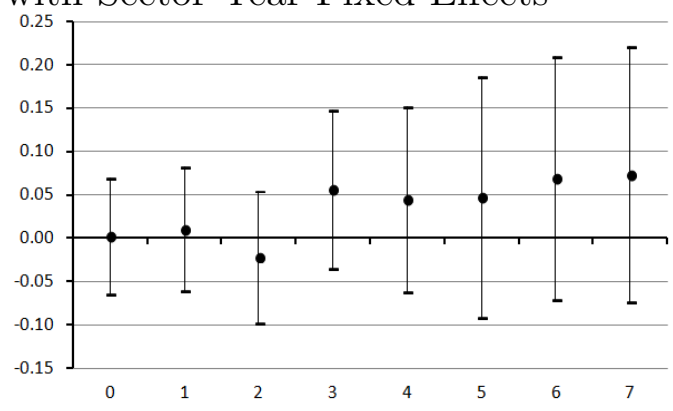

with Sector-Year Fixed-Effects

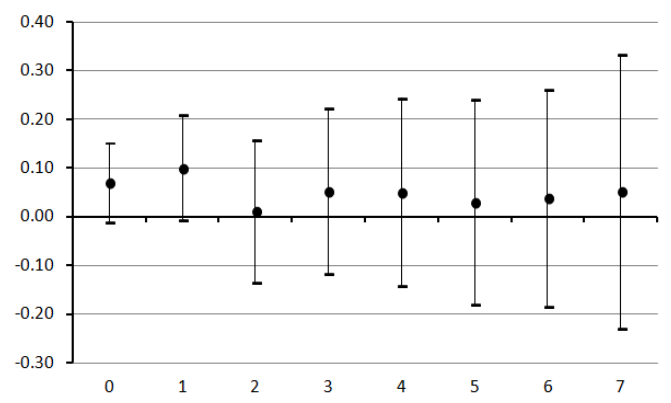

Figure 4.7: Effects of Privatization on TFP and wedges of labor and capital. Balanced panel. Panels A, B and C present the $\delta$ coefficients displayed in equations 4-1, 4-3 and 4-2. Vertical bands display $90 \%$ confidence intervals constructed with robust standard errors. Panel A: number of Observations is 2907, and clusters, 140; Panel B: number of Observations is 2904, and clusters, 140; Panel C: number of Observations is 2907, and clusters, 140. 
Panel A: wedge on Labor $\left(\left|\ln \left(\tau^{L}\right)\right|\right)$

with Year Fixed-Effects

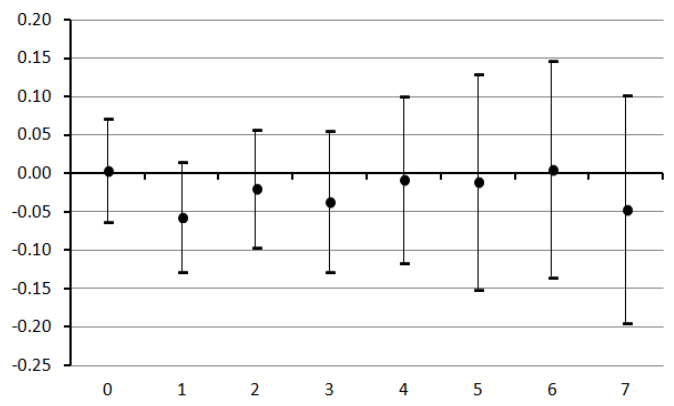

Panel B: wedge on Capital $\left(\left|\ln \left(\tau^{K}\right)\right|\right)$

\section{with Year Fixed-Effects}

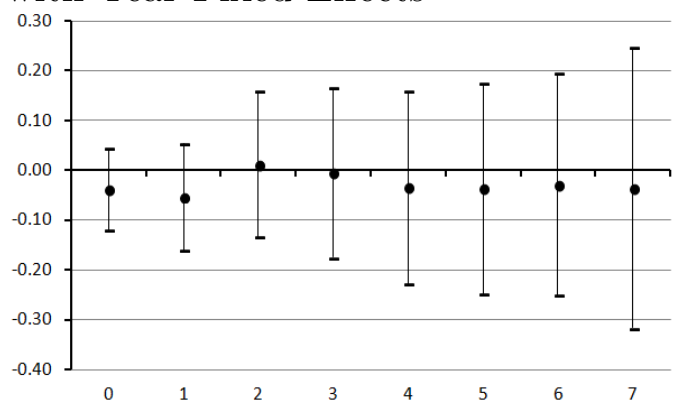

with Sector-Year Fixed-Effects

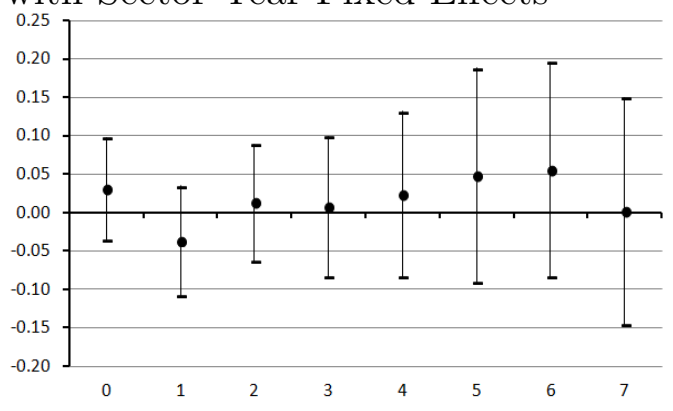

with Sector-Year Fixed-Effects

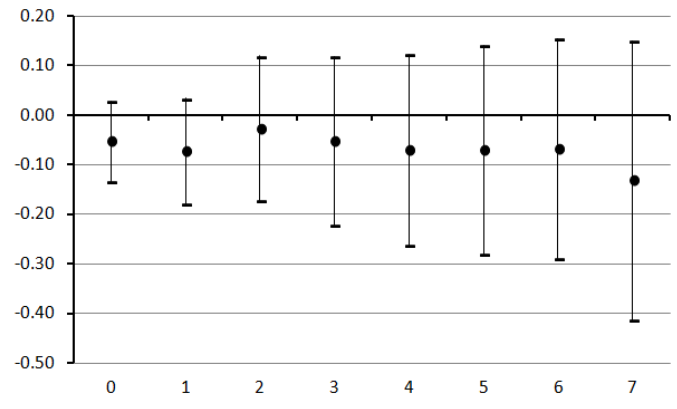

Figure 4.8: Effects of Privatization on TFP and wedges of labor and capital. Balanced panel. Panels A abd B present the $\delta$ coefficients displayed in equations 4-8 and 4-7. Vertical bands display $90 \%$ confidence intervals constructed with robust standard errors. Panel A: number of Observations is 8452, and clusters, 814; Panel B: number of Observations is 8500, and clusters, 815. 
Panel A: TFP $(\omega)$

with Year Fixed-Effects

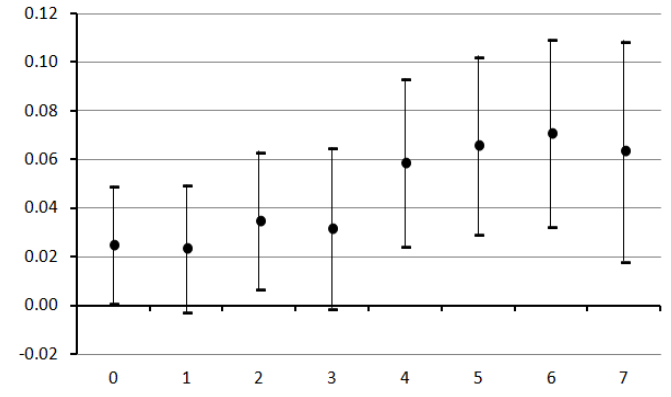

Panel B: wedge on Labor $\left(\ln \left(\tau^{L}\right)\right)$

with Year Fixed-Effects

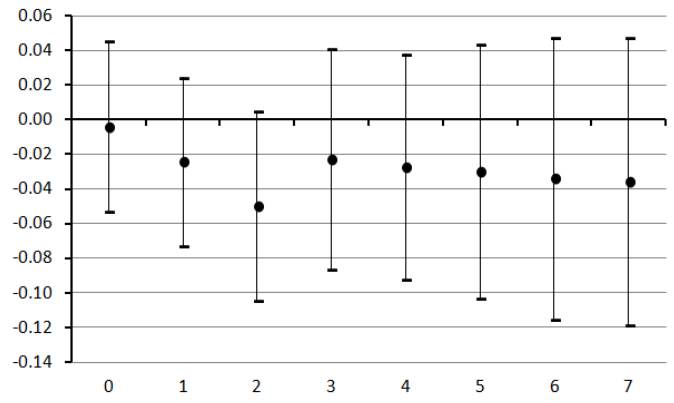

Panel C: wedge on Capital $\left(\ln \left(\tau^{K}\right)\right)$

with Year Fixed-Effects

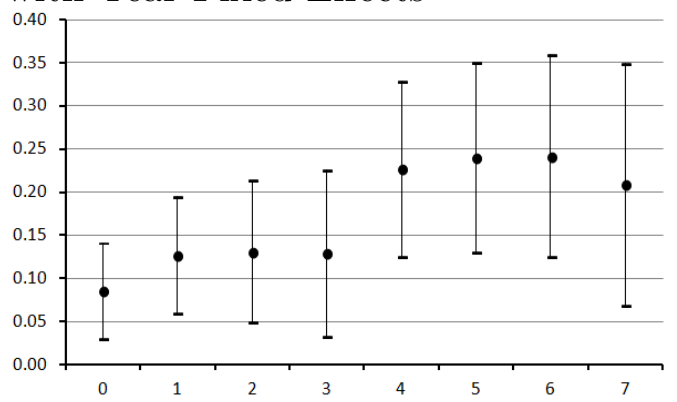

with Sector-Year Fixed-Effects

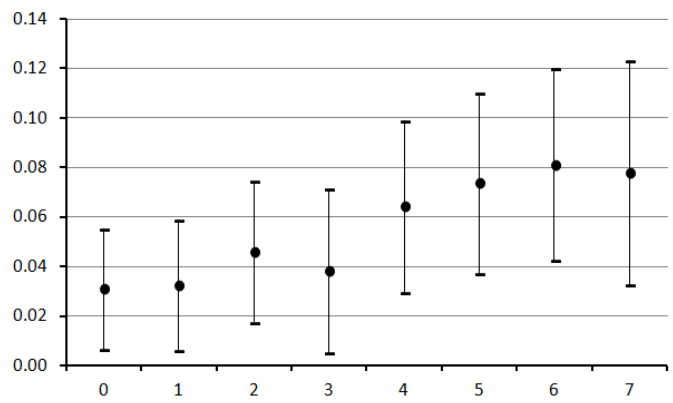

with Sector-Year Fixed-Effects

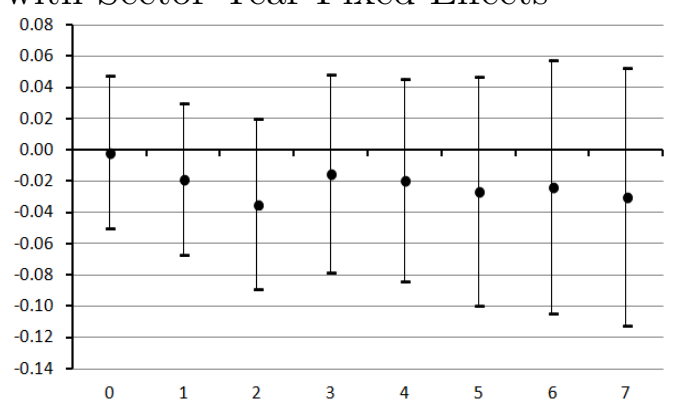

with Sector-Year Fixed-Effects

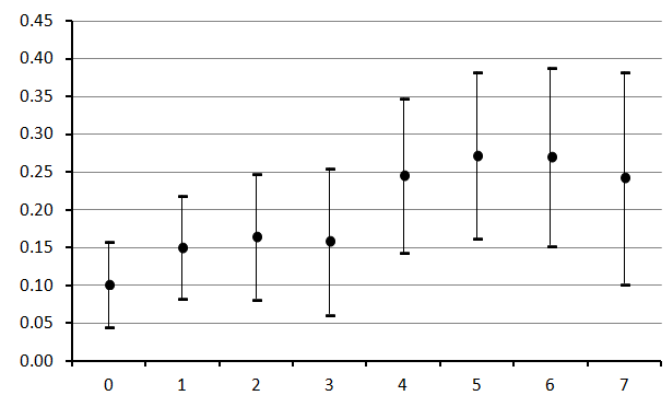

Figure 4.9: Effects of Privatization on TFP and wedges of labor and capital. Firms observed for 10 years or more. Panels A, B and $\mathrm{C}$ present the $\delta$ coefficients displayed in equations 4-1, 4-3 and 4-2. Vertical bands display $90 \%$ confidence intervals constructed with robust standard errors. Panel A: number of Observations is 6913, and clusters, 418; Panel B: number of Observations is 6864, and clusters, 417; Panel C: number of Observations is 6906, and clusters, 418. 
Panel A: wedge on Labor $\left(\left|\ln \left(\tau^{L}\right)\right|\right)$
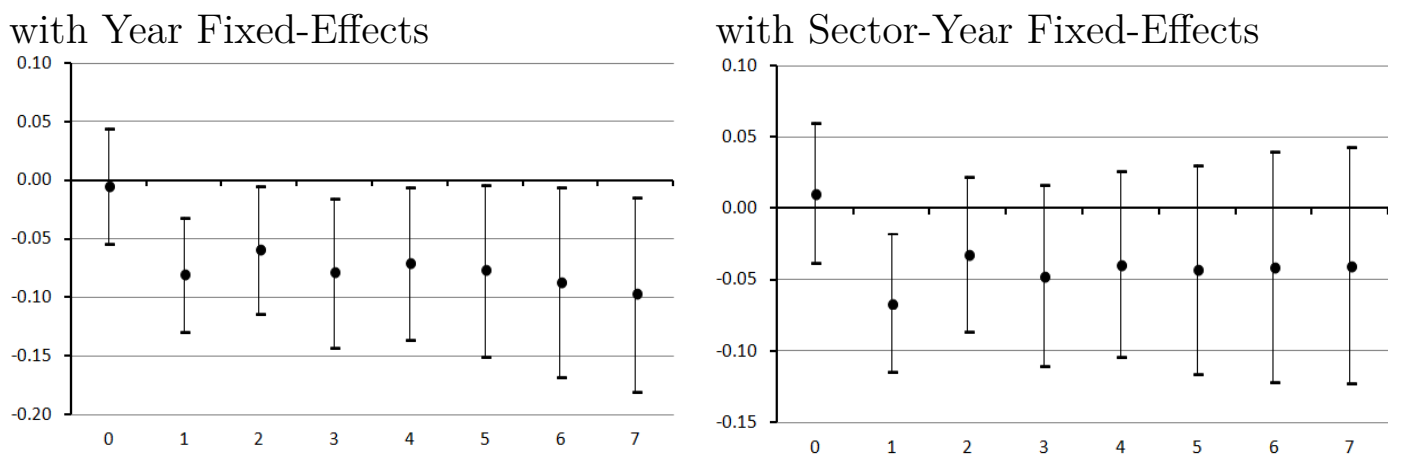

Panel B: wedge on Capital $\left(\left|\ln \left(\tau^{K}\right)\right|\right)$

\section{with Year Fixed-Effects}

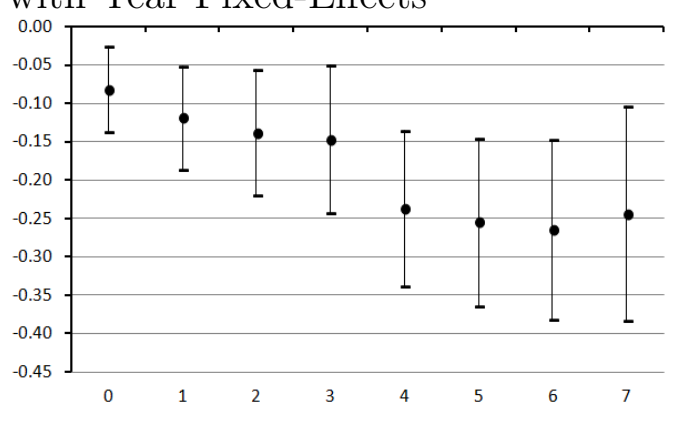

with Sector-Year Fixed-Effects

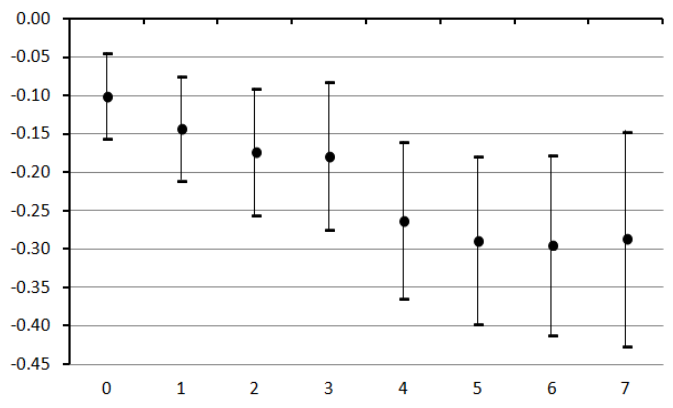

Figure 4.10: Effects of Privatization on TFP and wedges of labor and capital. Firms observed for 10 years or more. Panels A, B and C present the $\delta$ coefficients displayed in equations 4-1, 4-3 and 4-2. Vertical bands display $90 \%$ confidence intervals constructed with robust standard errors. Panel A: number of Observations is 6913, and clusters, 418; Panel B: number of Observations is 6864, and clusters, 417; Panel C: number of Observations is 6906, and clusters, 418. 


\section{5}

\section{Conclusions}

With data on Brazilian firms, we were able to asses whether privatization has affected the efficiency of SOEs across two dimensions. Productive and allocative efficiency. As it turns out, privatization seems to have positively affected both of these dimensions. As expected, the impact on productive efficiency seems to be the main channel through which firms lower their costs. Nevertheless, allocative efficiency is still economically relevant.

The main dimension firms adjust in their allocative efficiency is by adjusting capital. However, it seems after privatization, firms typically change their allocation of labor. But it seems this shift does not configure in a clear enhancement of productive efficiency.

Our results also point in the direction that small firms may be more affected by privatization than large firms. Further research on this heterogeneity would be relevant especially since, from a policy perspective, the privatization of large firms is a much more delicate subject and should be dealt with more thought than the privatization of small SOEs. 


\section{Bibliography}

Anuatti-Neto, F., Barossi-Filho, M., De Carvalho, A. G., and Macedo, R. B. M. (2003). Costs and benefits of privatization: evidence from brazil.

Arnold, D. (2018). The impact of privatization of state-owned enterprises on workers. Available at SSRN 3278753.

Borusyak, K. and Jaravel, X. (2017). Revisiting event study designs. Available at SSRN 2826228.

Brandt, L., Van Biesebroeck, J., Wang, L., and Zhang, Y. (2017). Wto accession and performance of chinese manufacturing firms. American Economic Review, 107(9):2784-2820.

Brown, J. D., Earle, J. S., and Telegdy, A. (2006). The productivity effects of privatization: Longitudinal estimates from hungary, romania, russia, and ukraine. Journal of political economy, 114(1):61-99.

Chen, Y., Igami, M., Sawada, M., and Xiao, M. (2018). Privatization and productivity in china. Available at SSRN 2695933.

De Loecker, J. and Eeckhout, J. (2017). The rise of market power and the macroeconomic implications. Technical report, National Bureau of Economic Research.

De Loecker, J., Goldberg, P. K., Khandelwal, A. K., and Pavcnik, N. (2016). Prices, markups, and trade reform. Econometrica, 84(2):445-510.

De Loecker, J. and Warzynski, F. (2012). Markups and firm-level export status. American economic review, 102(6):2437-71.

Gandhi, A., Navarro, S., and Rivers, D. A. (2018). On the identification of gross output production functions. Technical report, CHCP Working Paper.

Griliches, Z. and Mairesse, J. (1995). Production functions: the search for identification. Technical report, National Bureau of Economic Research.

Haltiwanger, J., Kulick, R., and Syverson, C. (2018). Misallocation measures: The distortion that ate the residual. Technical report, National Bureau of Economic Research. 
Hsieh, C.-T. and Klenow, P. J. (2009). Misallocation and manufacturing tfp in china and india. The Quarterly journal of economics, 124(4):1403-1448.

Megginson, W. L. and Netter, J. M. (2001). From state to market: A survey of empirical studies on privatization. Journal of economic literature, 39(2):321389.

Olley, G. S. and Pakes, A. (1996). The dynamics of productivity in the telecommunications equipment industry. Econometrica, 64(6):1263-1297.

Petrin, A. and Sivadasan, J. (2013). Estimating lost output from allocative inefficiency, with an application to chile and firing costs. Review of Economics and Statistics, 95(1):286-301.

Syverson, C. (2011). What determines productivity? Journal of Economic literature, 49(2):326-65. 


\section{Appendix}

\section{1}

\section{Dealing with the noise in Legal Nature data}

The information on the legal nature of firms provided by RAIS is quite noisy. Most likely, this is due to the fact that it is self-reported by the firm. There are multiple problems with them. One problem is that firms with multiple establishments have establishments with different legal nature. To deal with this, we only consider the legal nature of the head office as the legal nature of the firm.

A second problem is that there are many firms that change their legal nature very quickly. For example, it reports that it is a private firm in year $t-1$, an SOE in year $t$, and private again in year $t+1$. In all instances when this happens, we consider the firm to be private in year $t$ as well. There are also firms that report being SOE in year $t-1$, private in $t$ and SOE again in year $t+1$. We consider these firms to be SOE in $t$ as well.

Finally, we exclude from our study, firms that report being privatized more than once after the previous adjustments.

\section{2}

\section{Production Function Estimation and Variables used}

We assume the log of the production function as follows

$$
\begin{aligned}
f(\cdot)= & \left(\begin{array}{c}
\gamma_{0}+\gamma_{k} k_{j t}+\gamma_{l} l_{j t}+\frac{\gamma_{m}}{2} m_{j t}+\gamma_{k k} k_{j t}^{2}+\gamma_{l l} l_{j t}^{2} \\
+\frac{\gamma_{m m}}{3} m_{j t}^{2}+\gamma_{k l} k_{j t} l_{j t}+\frac{\gamma_{k m}}{2} k_{j t} m_{j t}+\frac{\gamma_{l m}}{2} l_{j t} m_{j t}
\end{array}\right) m_{j t} \\
& +\beta_{l} l_{j t}+\beta_{k} k_{j t}+\beta_{l l} l_{j t}^{2}+\beta_{k k} k_{j t}^{2}+\beta_{l k} l_{j t} k_{j t}
\end{aligned}
$$

This amounts to approximating the elasticity of intermediate consumption $\theta^{M}\left(M_{j t}, K_{j t}, L_{j t}\right)$ and $C\left(K_{j t}, L_{j t}\right)$ by second degree Taylor expansions, since

$$
\theta^{M}\left(K_{j t}, L_{j t}, M_{j t}\right)=\left(\begin{array}{c}
\gamma_{0}+\gamma_{k} k_{j t}+\gamma_{l} l_{j t}+\gamma_{m} m_{j t}+\gamma_{k k} k_{j t}^{2}+\gamma_{l l} l_{j t}^{2} \\
+\gamma_{m m} m_{j t}^{2}+\gamma_{k l} k_{j t} l_{j t}+\gamma_{k m} k_{j t} m_{j t}+\gamma_{l m} l_{j t} m_{j t}
\end{array}\right)
$$


We plug this formula in equation 3-9 and regress it using nonlinear least squares. We then calculate the integral in equation 3-10 by

$$
\int \frac{\hat{\theta}^{M}\left(L_{j t}, K_{j t}, M_{j t}\right)}{M_{j t}} d M_{j t}=\left(\begin{array}{c}
\hat{\gamma}_{0}+\hat{\gamma}_{k} k_{j t}+\hat{\gamma}_{l} l_{j t}+\frac{\hat{\gamma}_{m}}{2} m_{j t}+\hat{\gamma}_{k k} k_{j t}^{2}+\hat{\gamma}_{l l} l_{j t}^{2} \\
+\frac{\hat{\gamma}_{m m}}{3} m_{j t}^{2}+\hat{\gamma}_{k l} k_{j t} l_{j t}+\frac{\hat{\gamma}_{k m}}{2} k_{j t} m_{j t}+\frac{\hat{\gamma}_{l m}}{2} l_{j t} m_{j t}
\end{array}\right) m_{j t}
$$

and compute

$$
\mathcal{Y}_{j t}=y_{j t}-\int \frac{\hat{\theta}^{M}\left(L_{j t}, K_{j t}, M_{j t}\right)}{M_{j t}} d M_{j t}-\hat{\varepsilon}_{j t}
$$

We then approximate $h(\cdot)$ of equation $3-12$ by a 4 th degree polynomial, i.e,

$$
h\left(\omega_{j t-1}, S O E_{j t}\right)=\sum_{r=1}^{4} \alpha_{r} \omega_{j t-1}^{r}+S O E_{j t} \sum_{r=1}^{4} \alpha_{r}^{S O E} \omega_{j t-1}^{r}
$$

For every vector of $\beta=\left(\beta_{l}, \beta_{k}, \beta_{l l}, \beta_{k k}, \beta_{l k}\right)$, we compute

$$
C\left(K_{j t}, L_{j t} ; \beta\right)=\beta_{l} l_{j t}+\beta_{k} k_{j t}+\beta_{l l} l_{j t}^{2}+\beta_{k k} k_{j t}^{2}+\beta_{l k} l_{j t} k_{j t}
$$

Since $\omega_{j t}=\mathcal{Y}_{j t}-C\left(K_{j t}, L_{j t} ; \beta\right)$, from equation $3-13$

$$
\mathcal{Y}_{j t}-C\left(L_{j t}, K_{j t} ; \beta\right)=\lambda_{t}+h\left(\mathcal{Y}_{j ; t-1}-C\left(L_{j t-1}, K_{j t-1}\right)\right)+\eta_{j t}
$$

given $\beta$, we can estimate the vector $\left(\lambda_{t}\right)_{t=1996}^{2016}$, the vector $\alpha=\left(\alpha_{1}, \alpha_{2}, \alpha_{3}, \alpha_{4}\right)$ and the vector $\alpha^{S O E}=\left(\alpha_{1}^{S O E}, \alpha_{2}^{S O E}, \alpha_{3}^{S O E}, \alpha_{4}^{S O E}\right)$ by OLS. We then estimate $\beta$ by GMM, using the moment condition expressed in equation 3-16.

As for the variables, we proxy $Y_{j t}$ and $P_{t}^{Y} Y_{j t}$ by gross value of industrial production (which is reported by variable x 21 of PIA/IBGE). We proxy $M_{j t}$ and $P_{t}^{M} M_{j t}$ with costs of materials and energy consumed and services provided by third parties and (which is reported by variables x26, x27, x28, x29, x31).

As for labor, the information collected by IBGE allows us to observe $L_{j t}$ (reported by x01) and $w_{t} L_{j t}(\mathrm{x} 42)$ separately.

We constructed the capital stock series. For each firm, we take the average of all the depreciation it reports (x39) and assume this to be $5 \%$ of the initial capital stock of the firm. With the initial capital stock, we construct the rest of the series by, for each year, summing investments (x52 and x53) and subtracting liquidations (x54) and $5 \%$ of the previous year capital stock. We also sum for each year, the expenditures with rents (x36) and leases (x37).

Finally, we trim our sample to reach credible elasticity estimates. We ignore the observations where the firm reports to have spent less than $5 \%$ or more than $100 \%$ of its revenue with intermediate consumption. 


\section{3}

\section{Wedges under GNR assumptions}

Suppose the perceived price of capital and labor are distorted. Assume also that intermediate goods is a flexible input and capital and labor are quasifixed, and that firms are price takers and maximize discounted profits. Suppose also that in $t$ each firm knows the vector of prices in year $t+1$ (we make this hypothesis so that our distortion measure of prices also captures the errors of the manager's predictions of the vector of prices in $t+1)$. Then firms solve:

$$
\begin{array}{r}
V\left(L_{j t}, K_{j t}\right)=\max _{M_{j t}, L_{j ; t+1}, K_{j ; t+1}}\left\{P_{j t}^{Y} Y_{j t}-P_{t}^{M} M_{j t}-\tau_{j t}^{L} w_{t} L_{j t}-\tau_{j t}^{K} r_{t} K_{j t}\right. \\
\left.+\psi \mathbb{E}\left[V\left(K_{t+1}, L_{t+1}\right) \mid \mathcal{I}_{j t}\right]\right\}
\end{array}
$$

where $V(\cdot)$ is the value function and $\psi \in(0,1)$ is a discount factor.

We can write $M_{t}=M\left(L_{j t}, K_{j t}\right)$ as the materials used by a firm given the state variables. Thus, we can separate the firm's problem regarding the short term, and for the next year term. In $t$, the firm maximizes

$$
\mathbb{E}\left[P_{t}^{Y} Y_{j ; t+1}-P_{t+1}^{M} M\left(K_{j ; t+1}, L_{j ; t+1}\right)-\tau_{j t}^{L} w_{t+1} L_{j ; t+1}-\tau_{j t}^{K} r_{t+1} K_{t+1} \mid \mathcal{I}_{j t}\right]
$$

If take the derivative with respect to $L_{j ; t+1}$, we get:

$$
\mathbb{E}\left[\left(P_{t+1}^{Y} \frac{\partial Y}{\partial M}-P_{t+1}^{M}\right) \frac{\partial M}{\partial L}+P_{t+1}^{Y} \frac{\partial Y}{\partial L}-\tau_{j t}^{L} w_{t+1} \mid \mathcal{I}_{j t}\right]=0
$$

We, then, note that

$$
\begin{aligned}
\frac{\partial M}{\partial L} \frac{L}{M} & =\frac{\partial \log M}{\partial \log L}= \\
& =-\frac{\frac{\partial \log Y}{\partial \log L}}{\frac{\partial \log Y}{\partial \log M}}=-\frac{\theta^{L}}{\theta^{M}}
\end{aligned}
$$


And, we simply rewrite the FOC as,

$$
\begin{aligned}
\mathbb{E} & {[\frac{P_{t+1}^{Y} Y_{j ; t+1}}{w_{t+1} L_{j ; t+1}} \underbrace{\left(\frac{\partial Y}{\partial L} \frac{L_{j ; t+1}}{Y_{j ; t+1}}\right)}_{=\theta^{L}}} \\
& +\frac{P_{t+1}^{Y} Y_{j ; t+1}}{w_{t+1} L_{j ; t+1}} \underbrace{\left(\frac{\partial Y}{\partial M} \frac{M_{j ; t+1}}{Y_{j ; t+1}}\right)\left(\frac{\partial M}{\partial L} \frac{L_{j ; t+1}}{M_{j ; t+1}}\right)}_{=\theta^{M}\left(-\frac{\theta^{L}}{\theta_{M}}\right)} \\
& -\frac{P_{t+1}^{M} M_{j ; t+1}}{w_{t+1} L_{j ; t+1}} \underbrace{\frac{\partial M}{\partial L} \frac{L_{j ; t+1}}{M_{j ; t+1}}}_{=\left(-\frac{\theta^{L}}{\theta_{M}}\right)}-\tau_{j t}^{L} \mid \mathcal{I}_{j t}]=0
\end{aligned}
$$

which gives us:

$$
\mathrm{E}\left[\tau_{j t}^{L} \mid \mathcal{I}_{j t}\right]=\mathbb{E}\left[\frac{\theta^{L}(\cdot)}{\theta^{M}(\cdot)} \frac{P_{t+1}^{M} M_{j ; t+1}}{w_{t+1} L_{j ; t+1}} \mid \mathcal{I}_{j t}\right]
$$

The same argument could be made to $\tau_{j t}^{K}$

\section{4 \\ Weighted Regressions}

We investigate whether larger firms were more or less affected by privatization. We do this by regressing equations 4-1, 4-2, 4-3, 4-7 and 4-8 and weight each firm $j$ by the sum of the value of their output during our sample period. The results are presented in the figures below. We note that the estimated coefficients are similar to the estimated coefficients in the unweighted specifications. This suggests that the effect on TFP and in the wedges is homogeneous across firm size. However, since the production function is not homogeneous, the fact that the effect on $\omega$ is homogeneous across does not entail that the effect on costs is similar across sizes.

It should be noted, however, that in the weighted regressions, the coorrection of the perceived prices on labor is statistically significat and robust to sector-year fixed effects. So it seems the largest firms have received greater allocative efficiency gains. 
Panel A: TFP $(\omega)$

\section{Year Fixed-Effects}

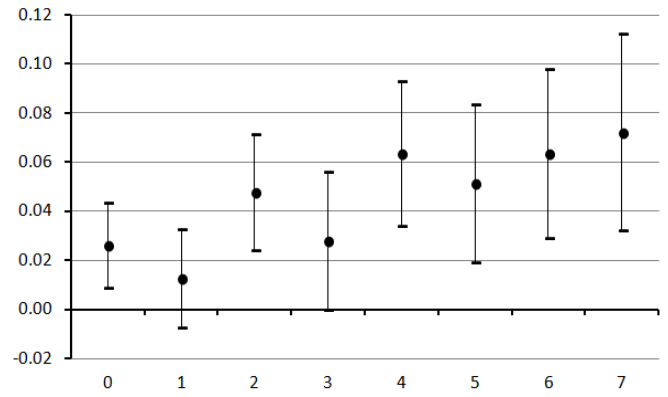

Panel B: wedge on Labor $\left(\ln \left(\tau^{L}\right)\right)$

with Year Fixed-Effects

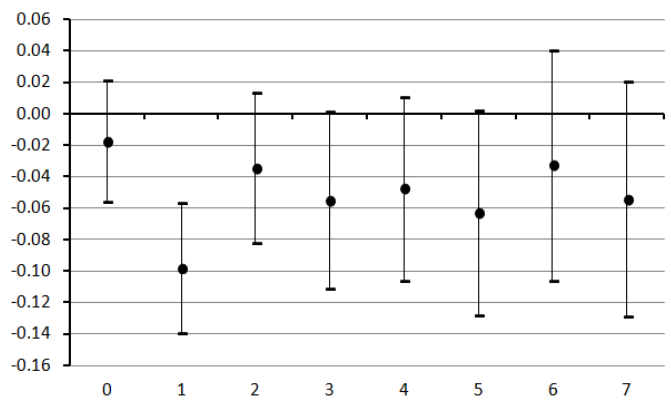

Panel C: wedge on Capital $\left(\ln \left(\tau^{K}\right)\right)$

with Year Fixed-Effects

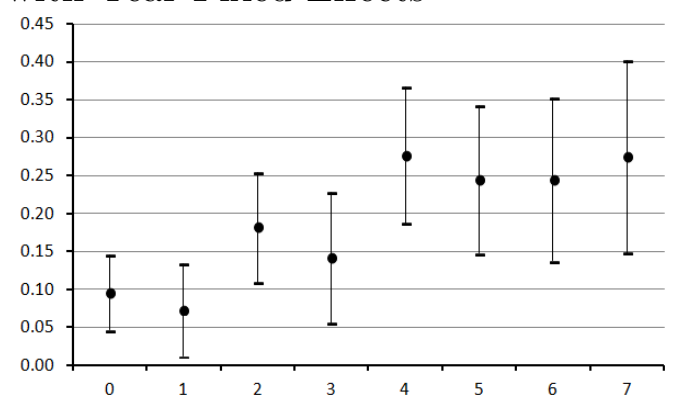

Sector-Year Fixed-Effects

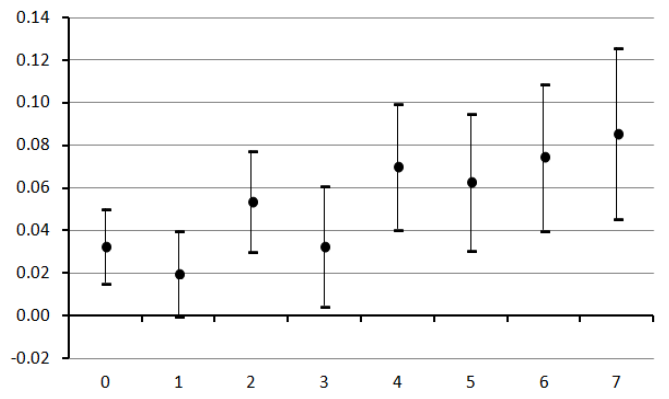

with Sector-Year Fixed-Effects

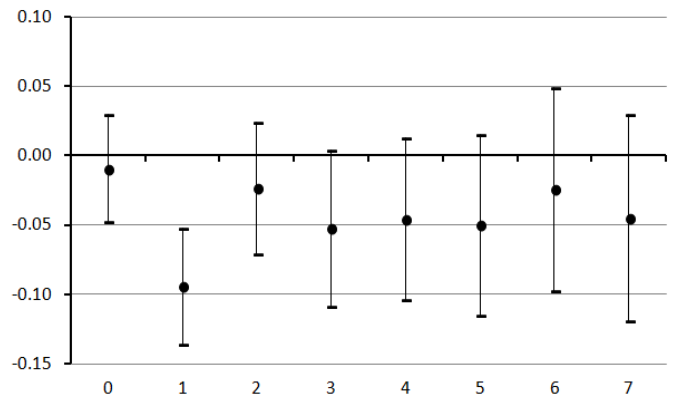

with Sector-Year Fixed-Effects

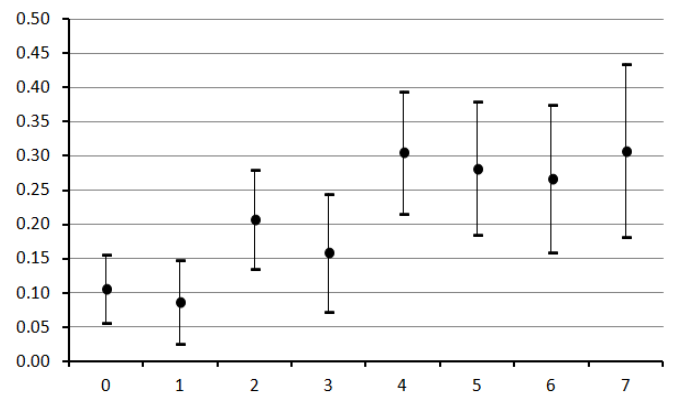

Figure 6.1: Effects of Privatization on TFP and wedges of labor and capital. Panels A, B and C present the $\delta$ coefficients displayed in equations 4-1, 4-3 and $4-2$. Clusters weighted by sum of product value. Vertical bands display $90 \%$ confidence intervals constructed with robust standard errors. Panel A: number of Observations is 9245, and clusters, 1080; Panel B: number of Observations is 9187, and clusters, 1079; Panel C: number of Observations is 9234, and clusters, 1080. 
Panel A: wedge on Labor $\left(\left|\ln \left(\tau^{L}\right)\right|\right)$

with Year Fixed-Effects

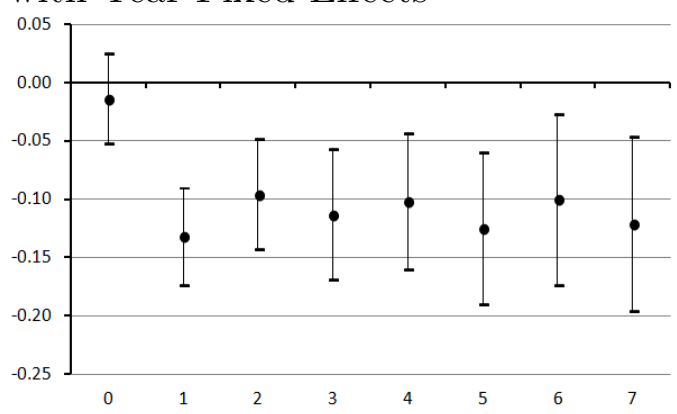

Panel B: wedge on Capital $\left(\ln \left(\tau^{K}\right)\right)$

with Year Fixed-Effects

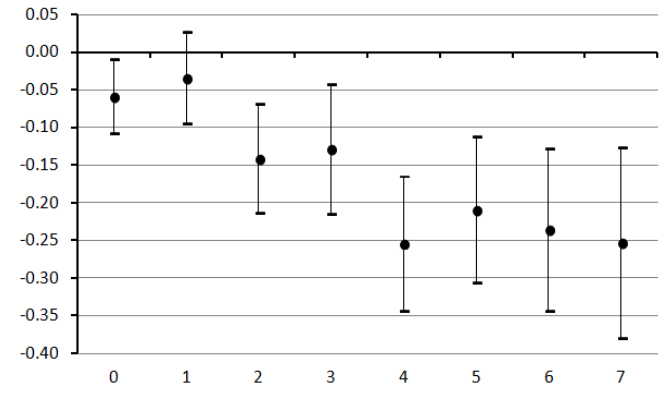

with Sector-Year Fixed-Effects

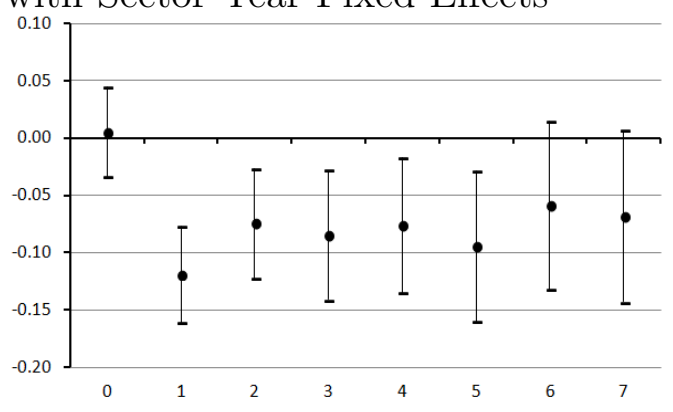

with Sector-Year Fixed-Effects

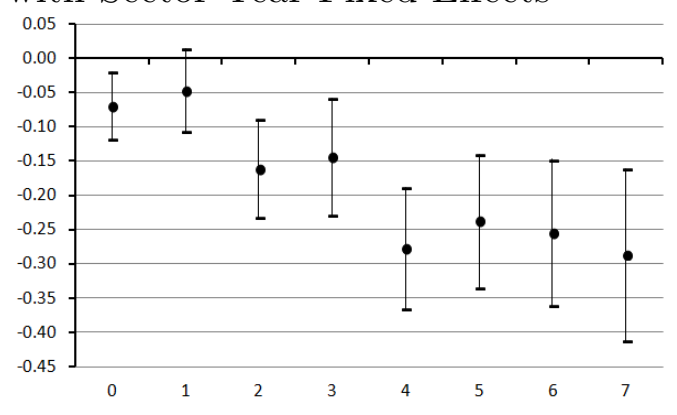

Figure 6.2: Effect of Privatization on allocative efficiency. Panels A and B present the $\delta$ coefficients displayed in equations 4-8 and 4-7. Clusters weighted by sum of product value. Vertical bands display $90 \%$ confidence intervals constructed with robust standard errors. Panel A: number of Observations is 9187, and clusters, 1079; Panel B: number of Observations is 9234, and clusters, 1080. 